\title{
The transformation of social life and the transformation of autism in the 1960s
}

The change in meaning

The establishment of child psychology in the early twentieth century enabled a stable theory of the development of children's subjectivity to settle by the 1950s. This model can be characterised as one in which early infantile hallucinatory wishes, dreams and thoughts slowly come to be replaced by reality, and realistic representations in the mind, via the infant's everyday experience and interaction with objects. It was only behaviourists that challenged this theory, but as they had no replacement model for the development of subjectivity, all they could offer were criticisms rather than an alternative. However, by the 1960s, shifts began to take place that encouraged the development of new theories of the development of subjectivity in infants and children. These new models built on Cyril Burt's idea to use statistical analyses of populations in order to generate scientific proof for the development of conceptual awareness in children. Just as in all earlier theories of child development, these new theories of subjective development had the concept of autism at their core.

One important occurrence in the search for scientific proof for autism was the deconstruction of the concept; it was interrogated, probed and criticised to its limits so that by the end of the 1960s, the initial meaning of the word 'autism' was completely annihilated. In fact, the new 'autism' that was developed during the 1960s had the exact opposite meaning of that which had prevailed until the end of the 1950s. Whereas autism and its conceptual cousins - primary narcissism, autoerotism, etc. - had previously always referred to hallucinatory 
dreamlike imaginary thought that preceded the establishment of realistic thinking, 'autism' from the 1960s was used to refer to a lack of imagination, a lack of hallucinatory thought, a lack of creativity and a lack of dreams. It was a concept that was predicated on the absence of imagination. 'Autism' of the 1960s thus became the kernel for describing the development of subjectivity in infants and children, yet it also referred to a state of mind that completely lacked any content or any meaning of its own and which gained its meaning only via the instruments used to measure it. This chapter examines this radical transformation in the meaning of autism. It examines why the shift in meaning occurred by placing it into the context of legal and political changes in Britain concerning the rights of children, and the impact of these changes on the construction of scientific studies of children.

\section{The transformation of social life}

In order to effect a major shift in the meaning of autism, there also had to be a major shift in the organisation of social life. Such a transformation began in 1959. This was the year in which the Mental Health Act was passed, which led to the closure of long-stay institutions for children. It was the Mental Health Act 1959 that set the scene for the gradual establishment of a framework for children's rights that was not exclusionary but in fact encompassed rights to education and social care for all children, regardless of their mental state. This generated new ideas about who could be accepted and incorporated into a new model of society.

The 1960s was also a decade in which increased liberalism about social norms finally began to permeate everyday life and expression. A growing generation of grammar-school-educated critical thinkers was finally able to challenge the authority of traditional models of social progress and evolutionary development espoused by authorities such as Cyril Burt. On the international stage, the British Empire was in its death throes. Harold Macmillan's 'Winds of Change' speech to the parliament of South Africa in 1960 signalled full independence for former colonies and encouraged critical reflection on the wider ideologies of social and evolutionary progress that had sustained British imperialism. ${ }^{1}$ A larger, educated reading public encouraged the publication of 
new journals and critical reflections on public life, creating a broader counter-culture movement. At the same time, increased availability of television and radio media enabled a surge in alternative forms of 'pop' culture. New visions and versions of 'society' and new ways to investigate, explore and understand it were feeding into the university system via the growth and expansion of the social sciences as a rational, neutral form of social exploration, unshackled by the dogmas and prejudices of Darwinian models of social progress. ${ }^{2}$

In the domain of family life, women were slowly gaining the right to make decisions about their own fertility and reproduction. In the early 1960s, the contraceptive pill was introduced as a licensed drug and made available on the National Health Service (NHS). By 1969, around one-and-a-half million women in the UK were on the pill. ${ }^{3}$ In addition to this, the legalisation of abortion in 1967 gave new rights for women who had experienced rape or unwanted pregnancies. Whereas the 1950s offered women Bowlbyism, pro-natalism and the drudgery of housework, the 1960s gradually began to offer them new models of social engagement. This led to some easing of the extreme moralising that had surrounded women's lifestyle choices and which had led to such injustices as forced adoptions for unmarried mothers. ${ }^{4}$ Some of this moralising had occurred under the auspices of the Children Act 1948, much of which had to be reorganised and rebuilt as the rights of women to make their own choices were ratified.

It is in this context that we must view the radical changes taking place in the area of children's rights. As Mathew Thomson has argued, postwar models of child subjectivity had propagated a model of children as simply inactive victims or welfare beneficiaries rather than active agents. Critiques of this model of children as passive welfare recipients of health, education and family life at the behest of the government would be increasingly challenged in the 1960s via radical movements that presented new models of individual and social development. ${ }^{5}$ The Mental Health Act 1959 was so significant in this field because it led to major changes in the organisation of care, welfare and education services for children. Once 'mentally defective' children, who had previously been excluded from all discourse and discussions concerning children's rights and entitlements to psychological health under the Children Act 1948, began to be regarded as legitimate psychological citizens, there were huge repercussions for the organisation of both child and family life. 
Child laws that were focused on supporting family life and providing children with a right to normal social adjustment, as typified in the Children's Act 1948, were based on Tavistock models of child development. These had been dominant in the post-war era, helping to propagate a model of human relations that could be quickly adopted within models for welfare policy aimed at stabilising family and social relationships. Bowlby and Winnicott had disregarded the detailed problems of describing the origins of subjective awareness that had been raised in the Controversial Discussions and focused instead on the practicalities of mothering, influencing welfare policy and popular understandings of childcare. Up until the late 1950s, the concept of 'maladjustment' had framed policy discussions over the organisation and management of children's social welfare services to enable the most favoured outcomes. However, in the 1960s, a new psychology of autism was used to challenge the social ideology of intervening in, and supposedly rectifying, child 'maladjustment'. The sciences of instinct theory and ethology could no longer support the entire edifice of child psychology. New models to measure 'autism' were developed in the fields of both experimental psychology and psychiatric epidemiology.

\section{The unmaking of mental deficiency law and the making of autism law}

The concept of autism was first raised in parliament in May 1960 by the Conservative MP William Compton Carr. ${ }^{6}$ Carr was also vicepresident of branches of the National Society for the Prevention of Cruelty to Children and the Society for Mentally Handicapped Children. ${ }^{7} \mathrm{He}$ questioned the parliamentary secretary to the Ministry of Health, Edith Pitt, on why responsibility for 'mentally handicapped' children was not borne by the Ministry of Education. The prospect of improving the mental capacity of such children, or 'upgrading' them, was steadily growing and he argued that the government should ensure that research in this area be supported:

The most exciting thing, which is still a frontier to be crossed, is the work on causes and treatment of so-called autistic - sometimes called schizoid, sometimes psychotic - children, which is almost unknown territory. These children are apparently schizoids who live in a dream 
world. They seem intelligent, but it is impossible to touch them even with treatment that is nowadays giving success in 75 per cent of normal adult schizoids. We must pay attention to that factor. ${ }^{8}$

This was an important moment for all children defined with psychosis, schizophrenia and autism. Prior to this point, the developing subjectivity of these children was of interest to few people other than psychological professionals who worked with cases of borderline mental deficiency, such as Anthony, Cameron and Creak. However, in the 1960s, children with childhood psychosis became an issue that was relevant to everyone involved in the NHS and local authority administration. The catalyst for this change was the Mental Health Act 1959.

In 1954, the British government had established a Royal Commission on the Law relating to Mental Illness and Mental Deficiency. ${ }^{9}$ This was a response to growing dissent concerning the civil liberties of the mentally ill following the publication of the 1953 World Health Organization (WHO) report. ${ }^{10}$ Important members of the committee included Sir Russell Brain, a distinguished neurologist with an interest in perception and speech disorders in children, and Mrs Bessie Braddock, a Labour MP concerned with problems of urban poverty. ${ }^{11}$ The Percy Report argued that any individuals with 'mental' or 'personality' problems and illnesses should be treated under the law 'with no more restriction of liberty or legal formality than is applied to people who need care because of other types of illness, disability or social or economic difficulty.' ${ }^{12}$ It discredited most legal powers that had been employed to compel the mentally defective and insane to institutional treatment. ${ }^{13}$ However, the rights and liberties of children diagnosed with 'psychosis', 'schizophrenia' and 'autism' were not clear in the resulting legislation.

Numbers of patients registered at hospitals for mental defectives had risen steadily throughout the late 1940s and 1950s. The director of 'subnormality' research for the Wessex Hospital Board, Albert Kushlik, argued that these rises reflected the fact that minatory agencies such as the police or social workers sometimes used the law to abandon difficult children who presented challenges to society, yet who were not necessarily 'defective. ${ }^{14}$ This followed the spirit of the Wood Report in including 'social inefficiency' in the classification, but the notion that people, especially children, could be labelled in such a way was 
unacceptable to the new generation of social investigators, social scientists and psychologists. Statistics obtained from the Board of Control for 1955 revealed a total of 141,164 'defectives' certified under the Mental Deficiency Act. ${ }^{15}$ Although only 12.33 per cent of cases were under the age of sixteen, the majority of all defective cases were certified during childhood. For example, of the total 6,386 'defectives' ascertained in 1954, 73 per cent had been referred by local education authorities. ${ }^{16}$ Many who worked in deficiency institutions pointed out the difficulties of supervising large groups of child 'defectives' in institutions, as illustrated in Figure 3. ${ }^{17}$

The Mental Health Act 1959 brought the recommendations of the Percy Report into force in England and Wales, kickstarting a new approach to mental health across Britain. ${ }^{18}$ As a result of this, the terms 'defective', 'idiot', 'imbecile' and 'feeble-minded' were all abandoned as legal terms and replaced with the terms 'subnormal', 'severely subnormal' and 'psychopathic disorder.' ${ }^{19}$ The Percy Report argued that the term 'psychopathic' should replace 'feeble-minded' and 'moral defective', and other 'pathologically mentally abnormal' persons who would not previously have been classed as 'mentally defective. ${ }^{20}$ A number of debates then ensued in parliament regarding this definition of 'psychopath', which many regarded as too broad. ${ }^{21}$ In the 1959 Act, 'subnormality' was defined in relation to intelligence levels, and 'psychopathy' in relation to conduct, and both conditions had to be 'susceptible to medical treatment or other special care and training of the patient.'.2 In both cases, a type of child was created in law who was 'mentally disordered' yet susceptible to treatment, and this type of child entirely replaced the 'defective' child who was legally incapable of social transformation. However, what was to be done with this new social being was not clear.

It was still the duty of the medical officer to determine whether or not a child was educable. However, now the legal status of children who were 'ineducable' included both children who would have previously been termed 'defective' and those who were increasingly coming to be called 'psychotic'. These conditions were thus conflated in the eyes of the law. Most importantly, Section 8 of the Children Act 1948, and subsection (6) of Section 5 of the Matrimonial Proceedings (Children) Act 1958, which had given powers to medical officers to remove children from the care of local authorities and place them in hospitals and defective institutions, then ceased to have any effect. ${ }^{23}$ Local authority 


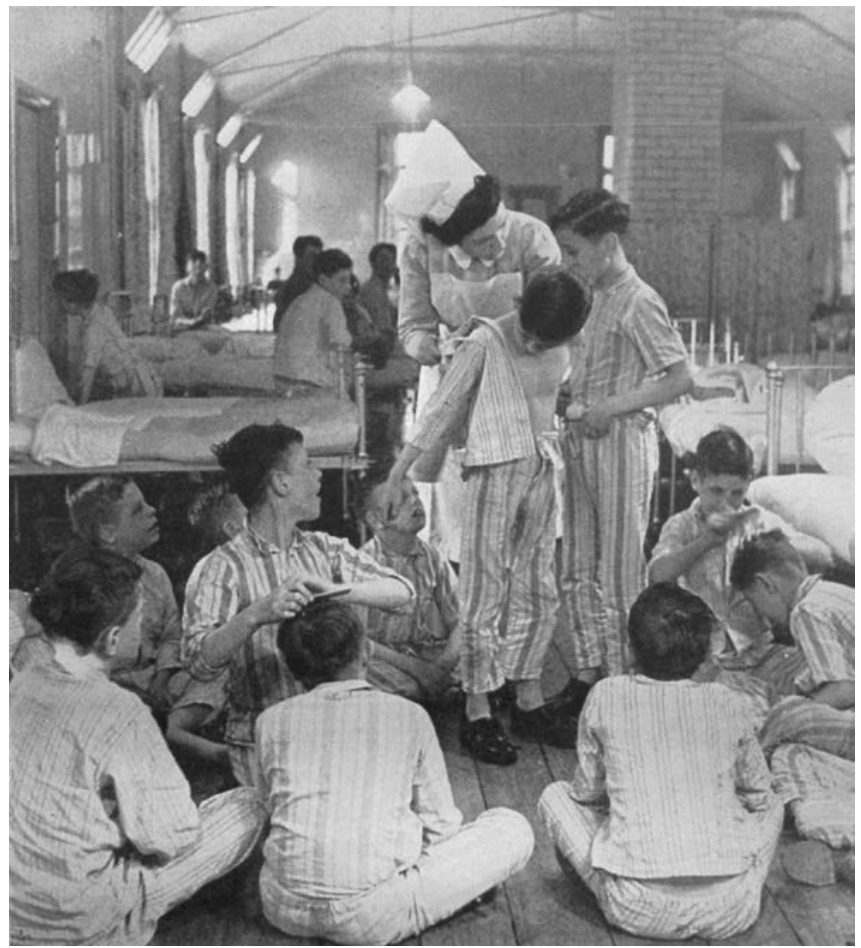

Figure 3 'A ward for imbeciles in a mental deficiency hospital', c.1956, from Leslie Hilliard and Brian Kirman, Mental Deficiency

(London: Churchill, 1957)

children's departments then assumed responsibility for all children, whether educable or not, unless they were thought to require specific short-term observation or hospital treatment for 'psychopathy' or 'subnormality. ${ }^{24}$ Children's departments also became responsible for all decisions over the long-term institutionalisation, education, adoption and care of children. This placed a huge pressure on children's departments that they had not previously experienced. It also opened their eyes to a generation of children who had been neglected within social and public policy. 
There were many inconsistencies in the implementation of the Mental Health Act. After it was passed, all registered 'defectives' were reclassified and responsibility for their care was transferred from hospital authorities under the NHS to local authorities. However, this handover was not accompanied by the transfer of hospital authorityrun institutions back to the management of local authorities. Local authorities were left with the task of building up a reserve of residential accommodation for such patients, yet had no infrastructure on which to assemble it. ${ }^{25}$ In practice, this meant that the buildings of 'defective' colonies and institutions acquired a new administrative role as hospitals for the 'mentally disordered' whilst still providing informal noncompulsory residential care for those now termed 'subnormal', under the guise of 'hospital treatment. ${ }^{26}$ Because individuals could no longer be committed under law purely on account of their 'subnormality', all child admissions into hospital or residential care took place via a negotiation between NHS hospitals and parents or local health care authorities. Doctors could only issue short-term enforced observation orders for children with 'psychopathy' or 'subnormality' for twenty-eight days. ${ }^{27}$ The Mental Health Act thus gave parents new powers to make decisions regarding the care and treatment of their children. Provided that a child had not been taken into local authority care under Section 1 of the Children Act 1948, all long-term admissions to hospital were voluntary and parents were at liberty to take their children home if they wanted to. ${ }^{28}$ After the Mental Health Act was passed, a child's long-term committal into institutional care could only occur at the behest of the parents or via the juvenile justice system. In Scotland, the 1960 Mental Health Act issued similar changes across Scotland.

This all created a major overhaul of the government systems designed to manage children's care. Just as a new generation of liberated women were finding their feet in the labour market and being granted improved rights to control their reproductive lives, the Mental Health Act also saw a huge change in the rights of women to keep their children at home, no matter what their intelligence level was. The new generation of social scientists also confirmed to the government that women welcomed this change. One major study conducted by Jack Tizard in the early 1960 s Mental Health surveyed 250 families of children who had previously been classified as 'imbeciles' or 'idiots' under the Mental Deficiency Act. He found that parents almost always reported that they wanted to 
keep their children at home, even if this compromised them in terms of their finances and social contacts. ${ }^{29}$ Although subnormality hospitals, managed by regional hospital boards under the Ministry of Health, were supposed to replace mental deficiency institutions in catering for children with 'subnormality', they had no legal right to detain such children and had to gain support from parents in doing so, and that was not happening. This put further pressure on the government to find new ways to support families and new ways to think about child development. Bowlby's notion that mothers were at the core of all problems of psychological development had thrived in a social welfare system that excluded 'mental defectives' and 'social inefficients', but it began to look quite ridiculous in a social welfare system that encompassed individuals with the full range of human mental capacity. New models for thinking about healthy child development, and for developing social welfare models to support it, were urgently required.

The bureaucratic problem: how many children are 'psychotic'?

The closure of mental deficiency institutions led to complete chaos in the administration of child welfare provisions for all children previously labelled as 'defective'. Local education authorities had adapted to dealing with the Board of Control when encountering difficult child cases and simply referred them on to this agency. Local authority children's departments had no expertise whatsoever in administering and catering to this group of children and referring them for placements. Children's departments also had to think very differently about what it meant to be a child 'in need of care'. This legal epithet thereafter no longer referred only to children who needed care because of parental harm or neglect, but also included children who were in need of care due to their own inherent mental 'subnormality'. This transition instituted a new way of thinking about children's psychological problems because it brought all of these problems to the attention of social work agencies, schools and local doctors. This initiated new ideas about what constituted a 'problem' child for state-managed agencies.

One important administrative problem that was quickly identified was that no one was entirely sure who should be responsible for 'psychotic' and 'severely maladjusted' children who would previously have 
been sent to the Board of Control because they were just too difficult for any other agency to deal with. After the passing of the Mental Health Act, it was unclear whether care for this group should be the responsibility of the local education authority or the local health authority. One major issue associated with this was the rather pressing one of how many children were actually 'psychotic', because the government needed numbers before they could begin to organise social services, education and other provisions for such children.

In 1961, the Ministry of Health began to collect information on 'the nature and extent of the hospital inpatient accommodation which is needed for mentally ill and maladjusted children and adolescents'. All existing children's units, including that based at the Maudsley, were asked how many beds they had for children under the age of twelve classed as either suffering from 'behaviour problems requiring shortterm treatment' or as 'psychotic and others requiring long-term treatment. ${ }^{30}$ There were sixteen inpatient units (containing a total of 340 beds), each specialising in particular types of case. For example, the inpatient unit at Belmont specialised in 'deaf psychotic' children; Pewsy Hospital in Wiltshire and Smith Hospital in Henley on Thames specialised in children with mental illness combined with 'subnormality'; The Park at Oxford specialised in what they termed 'neuropsychiatric' cases; and Whipps Cross in London took less severe cases as they were housed in a paediatrics department. The draft paper for the Standing Mental Health Advisory Committee (SMHAC) stated that provision was immediately required for children who needed long-term hospital treatment and that the Maudsley Hospital had stated this case most strongly. The committee suggested that twenty beds per million were required for children for short-term treatment and around twenty-five beds per region were required for long-term treatment for childhood psychosis. ${ }^{31}$

However, the committee was still unclear as to how many children actually had 'psychosis' or 'severe maladjustment' and thus would require special treatment. ${ }^{32}$ This was frustrating for both the Ministry of Education and the Ministry of Health because they could not plan services accordingly. Taking a standard view of national health requirements, the consensus amongst both ministries was that probably one unit for 'psychotic children' should be provided in each regional hospital board. However, Miss H. E. Clinkard of the Ministry of Education 
dryly pointed out that, in fact, 'neither Department had any real knowledge of what the total need amounted to in terms of places required. ${ }^{33}$ If it were not for the seriousness of the issue, the situation could appear somewhat farcical.

The fact that no department knew how many children were 'psychotic' added to legal issues emerging over the education of 'psychotic' children. Following the 1959 Mental Health Act, increasing numbers of parents began to use Section 57 of the Education Act 1944 to appeal against decisions that their child was 'ineducable'. In March 1962, Clinkard argued that 'psychotic' children in particular were making the decisions of local education authorities extremely difficult. She claimed that in reality there was little logic or justification to the decisions made about each child's ability to be educated. It did not help that local education authorities had no idea how to educate children who were 'psychotic. ${ }^{34}$ Faced with this complex conceptual problem about how to define and categorise a child's developing subjectivity and their ability to engage with the external world, the Education Department took a dim view. In March 1962, a major gathering was held regarding the issue of what to do in cases where parents claimed that their child was educable and 'psychotic'. Senior officials of the Ministry of Education, including Kingsley Whitmore, the Senior Medical Officer for the Department of Education and Science, argued that 'psychotic children' should be provided with 'hospital provision on a regional basis' because of the 'poor prognosis' of such cases and the 'inability of special schools to provide suitable conditions. They wished to shift responsibility for the problem onto the Ministry of Health, which they thought should provide services for 'autistic psychotics and extremely disturbed children', whom they combined under the same label. In the meantime, all cases of 'psychotic children' whose parents were appealing the classification of 'ineducable' would be sent directly to Kingsley Whitmore for a personal assessment. ${ }^{35}$ As a senior adviser, it was thought he would wield some clout when telling parents that their child was probably 'ineducable.' This was the line taken by the Ministry of Education in the early 1960s.

The Ministry of Health was generally prepared to take on the challenge of catering to 'psychotic' children, although only if they were 'in educable', an absurd tautology that was becoming increasingly difficult to bear. Nevertheless, the Health Department was still unclear as to how to establish hospital accommodation for 'psychotic' children 
because they were still not sure how many of them there were. In September 1962, one Ministry of Health official, P. Benner, argued that it was impossible to determine how many children had psychosis, claiming that

there is no real prospect of it being possible to make enquiries now which would yield information about future needs of sufficient reliability to be used for planning purposes. I am sure that the main need is to get the boards moving; and it might well be a positive disadvantage if at this stage we saddled ourselves with an estimated figure which turned out to be incorrect. ${ }^{36}$

However, because of the great uncertainty regarding the definition of children's psychological problems, they found it hard to reach even a ballpark figure and this was becoming increasingly problematic. This wrangling between central government departments was almost comical in the way that responsibility was endlessly shifted from one department to another as officials made wild guesses about the level of psychosis in the child population. Amidst all this debate, it was blatantly obvious that no one actually knew what childhood psychosis was.

In 1961, inspired by the complex dilemmas of those working in central government, Mildred Creak and Kenneth Cameron got together with several others to draw up a definitive list of diagnostic points that could be used to identify psychotic children with accuracy. This list would provide the basis for the first ever global epidemiological study of 'autism', so it was an important endeavour. However, it was not born out of methodical scientific enquiry, but rather the administrative nightmare in which the UK was engulfed. Other members of the committee who drew up the list included Miss Sylvia Ini, a psychiatric social worker who worked with 'psychotic' children at Great Ormond Street; Dr Guy Mitchell from the Tavistock Clinic Department for Children and Parents; Dr Ronald MacKeith, a paediatrician from Guy's Hospital; and Frank Orford Esq., a clinical psychologist who had previously worked at the Fountain Hospital for 'Mental Defectives'. There was no clear consensus on the terminology that should be used to describe the problem identified by the committee. Whilst some members wanted to call the phenomenon 'psychosis in childhood', others preferred the 'more specific' term 'childhood schizophrenia'. In the end, the committee reached a compromise with the awkward term 'schizophrenic 
syndrome in childhood, a classification that would never catch on. ${ }^{37}$ The committee agreed on nine diagnostic points that they claimed were crucial to a diagnosis. These were:

1. Gross and sustained impairment of emotional relationships with people;

2. Apparent unawareness of his own personal identity;

3. Pathological preoccupation with particular objects;

4. Sustained resistance to change in the environment;

5. Abnormal perceptual experience;

6. Acute, excessive and seemingly illogical anxiety;

7. Speech may have been lost or never acquired;

8. Distortion in motility patterns;

9. A background of serious retardation in which islets of normal, near normal, or exceptional intellectual function or skill may appear. ${ }^{38}$

Creak argued that if all psychiatrists could agree on the same diagnostic features then this 'would clear the way towards a common understanding and recognition of the phenomenological composition of the syndrome' and towards better treatment options. These nine diagnostic points came to be well known by all those interested in the field of childhood psychosis and autism research in Britain. They formed the basis of the 'second' autism, the autism that depicted absence of imaginative thinking and fantasy. This new 'style of reasoning' about autism was formulated as a direct response to government pressures and demands for numerical and statistical knowledge about the child population.

\section{The Society for Autistic Children and the pressure for educational rights}

For parents, Creak's definition of the 'schizophrenic syndrome in childhood' provided the ideal ammunition for confronting government departments and demanding action. This was because it gave a clear set of diagnostic points for a 'syndrome' that was not 'subnormality', hence not linked to intelligence levels, and therefore meant that children so diagnosed were 'educable'. In January 1962, the Autistic Children's Aid Society of North London was established by a group of parents who were frustrated with government inaction and took it upon themselves 
to provide long-term residential care 'for the treatment and education of autistic or psychotic children. ${ }^{39}$ It was parents who latched onto the diagnosis of 'autism', which they much preferred to 'psychosis' and 'schizophrenia' because of the social stigma attached to those labels. By 1963, the North London Society had already established themselves as a national body, the Society for Autistic Children (SAC), with additional goals to improve scientific research and public understanding of the condition. Two years later, Bernard Rimland and other parents formed a similar society in the USA.

As Chloe Silverman has pointed out in relation to the USA, parent groups were significant as they advocated strongly for children diagnosed with 'autism. ${ }^{40}$ Parent groups in Britain were also important in providing political clout and encouraging treatment and research. SAC campaigned directly to the Ministries of Health and Education and helped to push through reforms to ensure that children diagnosed with these conditions received education. However, in Britain, these changes were only possible after the 1959 Mental Health Act, as it was this Act that passed powers of institutional committal onto parents and also highlighted the predicament of 'psychotic' children who did not fit into prior classification systems.

In 1963, the term 'autistic' was beginning to be used frequently in administrative literature, following the lead of parent campaigners. In 1963, the Standing Health Advisory Committee was sent a memorandum from SAC written by John and Lorna Wing of the Social Psychiatry Research Unit at the Institute of Psychiatry. The Wings were also parents of a child with autism and this had led to their association with SAC. They had both trained in medicine at University College Hospital and then went into the field of psychiatry. Mildred Creak had introduced them to the topic of childhood schizophrenia and autism. ${ }^{41}$ The Wings would form the backbone to all changes in the administration and definition of autism in Britain. As parents, advocates, researchers and professionals at the Institute of Psychiatry, they had all perspectives on the topic covered. Their memorandum was intended to clarify the unique problems of autistic children, as opposed to any other type of child, and the educational and hospital services that they would require. It would become a historic document in redefining the rights of children labelled as 'autistic', yet it was also a historic document in redefining the rights of all children to an education, no matter what 
their supposed limitations were. The Wings were thus important political campaigners for all children's rights.

The Wings argued that it is now accepted that the processes underlying normal child development may go wrong in various ways', and that wholesale terms, such as 'mental subnormality', were not specific enough to plan 'detailed measures of treatment or education'. They further argued that if officials could recognise the 'specific handicap' of a child, then it was always much easier to manage their 'problem behaviour'. Clarifying their understanding of autism, they argued that "The term "autism" is a convenient label for a behavioural syndrome with a first onset in early childhood, in which the most obvious symptom is a difficulty in forming social relationships. ${ }^{22}$ Although 'childhood schizophrenia' had previously been used as a label, they thought that "autism" is preferable because of its neutrality and lack of implications about aetiology and prognosis. ${ }^{43}$ One of their claims was that if a child 'cannot make sense of what he sees or hears (who cannot recognise a lamp-post let alone a parent)', then they 'will clearly be autistic. ${ }^{44}$ However, they also argued that the condition was not necessarily associated with intelligence. In a review of seventy-four cases seen by Anthony and Cameron at the psychotic clinic (cases the Wings now classed as autistic), they found that 37 per cent had a 'nuclear' form that did not affect their intelligence at all. ${ }^{45}$ They argued that the discovery of 'autism' in a child 'gives rise to problems of treatment, education and management different to those found in other psychiatric disorders of childhood: ${ }^{46}$ They added that some 'dysphasias, agnosias and dyspraxias' should be included under the 'autism' label because children with these conditions often demonstrated 'several features of the autistic syndrome without social withdrawal, ${ }^{47}$ For these children, treatment should be based on a 'practical assessment of disabilities' followed by 'special educational methods'. In short, they argued that 'subnormality' was a useless label and that intelligence testing could not identify each child's specific problem well enough. Although ostensibly discussing 'autism', the Wings' memorandum was just as much a manifesto for special education as it was for autism per se. It was part of the wider movement within child psychology that aimed to identify autism in order to challenge a paternalistic model of welfare state provision for children with individual difference. In psychological language, the portrayal of 
individual difference was now increasingly being framed in terms of autism rather than maladjustment.

The Wings were unequivocal in their condemnation of long-stay institutional care. However, unlike Bowlby, who criticised institutional care for the mainstream population because it separated them from their mothers, the Wings criticised institutional care for all children of all intellectual levels. They did so primarily on the grounds that it was not stimulating enough. They argued that autistic children, in particular, needed even more individual attention than other children. As they put it, 'Certain kinds of environment are known to be harmful even to normal children - particularly the depriving and understimulating conditions of institutions and centres where staff cannot give individual attention to each child. Autistic children, because of their tendency to social withdrawal, are particularly vulnerable to such conditions. ${ }^{48}$ They highlighted the 'evils of large institutions' and pointed out that the best environment for autistic children was the family. ${ }^{49}$ This criticism of institutional care was becoming increasingly widespread by the early 1960s. In the late 1950s, Jack Tizard had gathered together several children from the Fountain Hospital for Mental Defectives and transferred them to a beautiful house in Surrey with a much higher staff ratio, aided by a grant from the Mental Health Research Fund. ${ }^{50}$ When tested, these children had increased their verbal age significantly compared to those left in hospital. They were also 'healthy, sun-tanned and alert' and played more co-operatively than those in hospital. Thus, Tizard and other Maudsley psychiatrists argued that all children, whatever their mental states, benefited from small care homes with a good allocation of adult staff, and this advice was echoed by the British Psychological Society. ${ }^{51}$ Tizard's 'Brooklands Experiment' later became a model of a treatment centre for children classed as 'subnormal. ${ }^{52}$ The BPS report claimed that 'children who show autistic or psychotic symptoms - at least 10 percent of the admissions in the present survey - tend to become even more withdrawn if left to their own devices. ${ }^{53}$ Unlike Bowlby and Winnicott's pronouncements on the necessity of maternal love, Tizard and the new autism psychologists regarded the problem of institutional care as primarily economic. These children needed greater financial assistance from government before they needed maternal love. They argued for smaller units or family care for children of all mental states. 
This work would lead to Tizard being appointed as a consultant adviser in mental subnormality to the Department of Health and Social Security from 1965 to 1975 . He later became a member of its Chief Scientists' Research Committee in 1973 and Consultant to the Home Office Research Unit in 1975. In a research capacity, Tizard was also Professor of Child Development at the Institute of Education from 1964 to 1971; chairman of the educational research board of the Social Science Research Council between 1969 and 1971; and president of the BPS from 1975 to 1976 . His portfolio of work as a psychologist and adviser instituted major changes with regard to the study and education of 'subnormal' populations. ${ }^{54}$

In 1963, SAC submitted a memorandum to the Ministers of Health and Education putting additional pressure on them to standardise their approach to 'autistic or psychotic' children. They argued that parents had to 'fight administrative confusion' as local education authorities often disagreed with local health authorities. They cited the case of one boy whose local education authority had claimed was 'maladjusted' and had asked the parents to select their own school whilst the local Medical Officer of Health put pressure on the parents to place him in a health authority-maintained 'Junior Training Centre' for 'subnormals'. SAC claimed that such inconsistencies in approach were appalling, and ultimately stated clearly that 'We are of the opinion that all children, however handicapped, should be the responsibility of the education authorities and that there should be legislation accordingly. ${ }^{55}$ This was a bold statement, impacting not only children deemed 'autistic' but all children regarded as 'ineducable'. SAC was therefore pushing for reforms that would inevitably affect all children whose care came under the health authorities. SAC criticised intelligence tests, not because of their economic bias or even their validity per se, but rather because they simply did not give 'autistic' children the time and space to express their full potential. They argued for early diagnosis, whilst simultaneously admitting their underlying motive was that 'early diagnosis will quickly reveal the lack' of facilities. ${ }^{56}$

Statutory machinery already existed for special classes to be run at established ESN schools, schools for the maladjusted and Home Tuition Units, and for classes to be established at a school. Section 56 of the Education Act 1944 had enabled local education authorities to establish 'home situation groups', which, if approved by the local 
education officer, could receive financial support from the government. SAC initially applied for government funding via these channels and then slowly began to expand their work. In July 1962, SAC had devised a model day and residential treatment/education centre for autistic children in London. They also argued for the establishment of family-style homes for children outside London, as well as specialist centres for adolescents. SAC was noncommittal on the efficacy of psychoanalytic psychotherapy in the early 1960s, arguing that it should be available on the NHS for autistic children because 'some children can be helped in this way', even if 'some members of the medical profession are not in favour of this treatment. ${ }^{57}$ Providing all of this help and medical support for autistic children was not cheap. In fact, one of the reasons why British research in the 1960s became so influential is that it was specifically devised to engage with government departments and to make arguments about why this particular group of children needed specialist support. It thus became quite flawless in execution.

When submitting costs to the Ministry of Education in the early 1960s, SAC stated that it is recognised that having 2 teachers to 5 children is enough to appal any self respecting financial officer', but tried to bring all on their side by arguing that it provided 'individual attention which is so necessary to engender confidence in these children. ${ }^{58}$ SAC pointed out that 'No specific courses for teaching autistic or psychotic children exist', but they recommended other training channels for the new teachers who would be required to educate this new group. The Wings had already begun to give guidance on particular teaching methods, such as the need to teach through action, pointing out that for one child, "Words (such as "Draw a circle") only became meaningful after the motor acts had been acquired', and that 'Such simple principles can be worked out for most autistic children and obviously help to accelerate their development.' SAC recommended courses for the training of teachers of ESN and maladjusted pupils, such as a one-year full-time course at the Institute of Education and the Department of Child Development, London, and similar courses run at the LCC and Reading University. Finally, Maria Grey College in Twickenham ran a training course for teaching 'backward children', which SAC also endorsed. ${ }^{59}$ This built on the methods of Stanley Segal, who had founded the Guild of Teachers of Backward Children and publishing Forward Trends in the Treatment of Backward Children between 1957 and $1966 .{ }^{60}$ In the 
mid-1960s, the guild had approached the Ministry of Health and the Department of Education and Science proposing an enquiry into special education and the needs of all children, including those then excluded from the school system. SAC also supported the Montessori and Steiner methods. Furthermore, they recommended that prospective staff could also adapt methods for teaching blind and deaf children. This appeal to enlist teachers from other fields was important because it helped to form a wider network of teachers and parents who were challenging the 'ineducability' of any child. They argued that their children were not really any different from 'deaf' or 'blind' children, whom the government had always recognised as legitimate subjects for education. These parallels would crystallize as theories of 'sensory impairment' and autism were developed. SAC also argued that the government must give grants to teach autistic children in independent schools if local authority schools could not provide proper education for them. ${ }^{61}$

New methods specifically designed for educating autistic children were often highlighted by SAC as important models from which to learn. At the Maudsley, some behaviourist experiments with language learning were trialled amongst children with the autism diagnosis, derived from the work of one of Skinner's colleagues, Charles Ferster, who claimed he had designed a way to teach language to children diagnosed with autism using an experimental room containing a range of bizarre devices including a pastry-vending machine, a pigeon contained within a transparent wall unit, a pin-ball machine, an eight-column sweet vendor modelled on a cigarette vending machine, a spinning colour wheel, an organ and a phonograph that played music. ${ }^{62}$ This work, the forerunner of Applied Behavioural Analysis, built on a body of research conducted in the late 1950s on the use of operant conditioning to teach speech to animals, children and mute schizophrenic adults, such as that carried out by Catherine Hayes, $\mathrm{H}$. Rheingold and W. Isaacs. ${ }^{63}$ These operant conditioning methods were trialled at the Maudsley and the British Autistic Society Schools from the mid-1960s, although they were quickly integrated into a uniquely British model for testing and responding to 'autistic' children based on sensory awareness. ${ }^{64}$

In the USA, behaviourist methods for treating autism became very popular. In Britain, these methods were viewed more skeptically, within a wider context of educational theory. There was concern about 
the fact that in the USA, purely 'behaviouristic' approaches were being applied directly to children when coupled with shock therapy. For example, I. O. Lovaas, one of the pioneers of behavioural therapy for 'schizophrenic' children at the Neuropsychiatric Institute of the University of California, Los Angeles (UCLA), argued that behaviouristic speech-training therapies avoided all attempts 'to respond to, or otherwise "understand", the child on the basis of his psychotic verbal or non-verbal communications. ${ }^{65}$ Lovaas later wrote on 'building social behaviour in autistic children by the use of electric shock', a rather incongruous idea, but he had a lot of support for his work. ${ }^{66}$ In the USA, the 1960s also saw a flood of experiments with LSD (d-lysergic acid diethylamide) in the 'treatment' of autism in children. Lauretta Bender conducted LSD experiments on children from the ages of four to fifteen years and argued that the drug improved children's 'verbalisations' and 'reality testing', whilst reducing their 'anxiety' and 'bizarre ideation'. Bender and her colleagues, by their own admission, had already experimented in treating autistic children with 'metrazol, electric convulsions, subshock insulin, many psychopharmaceutical agents, the milder antihistamines (Benabdryl), amphetamines, phenothiazines, reserpines, antidepressants, tranquilisers, etc.. ${ }^{67}$ This aggressive treatment culture would begin to wane by the late 1970s, but during the 1960s such experiments were trialled by researchers across the USA: for example, at the Mount Sinai Hospital New York Medical College and UCLA. ${ }^{68}$ British researchers were reluctant to adopt medical approaches and focused instead on educational methods that had a longer tradition in British special education.

Through their work with schools and universities, SAC sought to educate all educational and health professionals to see autism, to identify it and to diagnose it. As they put it: 'Through letters and articles in the medical press and through the distribution of diagnostic information, it [the Society] means to educate General Practitioners, Medical Officers, and Health Visitors to consider autism as a possible diagnosis for children whose intellectual processes fail to develop along normal lines. ${ }^{69}$ In January 1963, the society published a survey of 140 children whose parents regarded them as 'autistic' (105 boys and 35 girls), finding that over 50 per cent were still in Subnormality Hospitals and Training Centres or being cared for at home with no educational provision, a situation that was hugely unsatisfactory for their parents. ${ }^{70}$ They 
championed parents to become social activists and to use the diagnosis of autism in order to do so.

William Compton Carr, MP, was an important associate of SAC. After introducing the Houses of Parliament to the word 'autism' in the 1960s, he continued to emphasise the need for more research into child autism and psychosis. In a speech to the House of Commons in March 1963, Compton Carr argued for 'more and earlier diagnosis and more surveys to assess the need for services', 'more flexible educational special and medical services', 'a more open mind to unorthodox techniques', 'more residential care for all ages in schools and hospitals', 'more help for the family', 'more research and experimentation', 'more public understanding' and, last but not least, 'more money.71

By late 1963, a sea change was beginning to occur. The Special Education Sub-Committee at the Department of Education produced a report stating that:

Autistic is the name now given to severely disturbed psychotic children suffering from a form of childhood schizophrenia. They are unresponsive, withdrawn, non-communicating children who live in a dream world and are unable to form or sustain relationships with people, and are without sensory or other physical or mental defects that would account for this disability. ${ }^{72}$

This showed an acceptance that 'autistic' children differed from those with subnormality, although it maintained the first definition of autism as 'children who live in a dream world'. Nevertheless, it was the beginning of a shift in acknowledging education rights, although such rights still depended on the government knowing how many 'autistic' children there were, or how many 'psychotic' children there were. In the upper echelons of parliament, the Parliamentary Secretary to the Ministry of Education, Christopher Chataway, confirmed that there were now twenty-one hospital units located in England and Wales 'for severely maladjusted and psychotic children', based on figures from the Health Department, and that parental demands were beginning to be met. Although there was still a lot to be desired in terms of definition, this was an acknowledgement that the government was beginning to think differently about the rights of all children to be educated. Chataway claimed that he no longer thought of education purely in terms of economic return and pointed out that the Report by the Ministry's Chief 
Medical Officer on the Health of the Schoolchild had emphasised that no children should be excluded from the educational system without a prolonged trial of psychiatric and educational treatment. There was a minor caveat for those whose impairment of mental function was too gross for response to therapy ${ }^{73}$ However, the existence of this elusive 'ineducable' group would become increasingly difficult to prove. Most importantly, Chataway praised the work of researchers from the Institute of Psychiatry, highlighting the enthusiasm and general rhetoric of the period, adding: 'Whatever else can be said about the age in which we live, it is one in which we are learning to avoid the waste and grim frustration in human talent which has hitherto prevailed..$^{74}$ In July 1964, a meeting was held between members of the Department of Education and Science, the Ministry of Health and SAC to discuss state provision for autistic children. Baron argued that although Section 33 of the Education Act purported to provide for such a group, in fact, 'few were receiving specialist help to overcome their difficulty in communicating. Lorna Wing argued that 'the only way to assess the suitability of a child for education was to attempt to educate him', dismissing the expertise of Medical Officers of Health as the adjudicators of educational justice. Jack Tizard pointed out that his work with children at the Maudsley Unit had shown that children with IQs below 50 could be educated, arguing that 'I.Q. rating should not be regarded as the touchstone for educability' but should rather 'be employed constructively to identify a child's skills on which future progress could be based'. There could not have been a more damning critique of the Department of Education and Science's stance on 'ineducability'. Although the discussion was focused on 'autistic' and 'psychotic' children, it was clear this was developing into a wider critique of policy on all 'ineducable' children and the government were finally beginning to listen. ${ }^{75}$

Throughout all of these discussions, there was no clear figure on the exact number of autistic children, no clear definition of what 'autism' was and why it made a child 'educable'. Chataway had actually drawn attention to the effort being made by the London County Council to collect figures on the numbers of children with 'psychosis', as it was paramount to any government progression on provision. ${ }^{76}$ However, none of these attempts provided quite enough ammunition to fully challenge the government's stance on 'ineducability'. It would take the first epidemiological study of autism to do this. 


\section{The quantification of autism}

The first statistical study of 'autism' began in 1963 under the supervision of John Wing and Neil O'Connor. This attempt to make a previously immeasurable concept concerning the early stages of infantile development, autism, into an entity that was identifiable and measurable across populations would mark a radical shift in the conceptualisation of child development. As Rhodri Hayward has argued, the formation of what he refers to as 'the statistical psyche' can be traced to the late 1950s, when the association between historical truth and individual cure was broken down as claims made for the efficacy of psychoanalytic psychotherapy were confronted with new drug cures that worked without the need for a historical narrative. At the same time, new statistical instruments were rapidly being developed in the field of clinical psychology, such as Hans Eysenck's Maudsley Personality Inventory (1959) that enabled character to be assessed via aggregated scores rather than individual interviews. The tests of clinical psychologists were used for a major project in the quantification of the psyche that enabled tests for therapeutic efficacy and planning of clinical trials, right through to the planning of national mental health services. The creation of the randomised control trials in Wales in 1950 and publication of the first Diagnostic and Statistical Manual in the USA in 1952 provided new methods with which to measure the psyche in figures and statistics, and these methods became increasingly sophisticated. ${ }^{77}$ As Ian Hacking, Theodore Porter and others have explained, these instruments are part of wider historical trends that followed the rise of statistical thinking. ${ }^{78}$

Victor Lotter's attempt to develop a method to quantify autism in the early 1960s must, therefore, be viewed within this wider context. However, this particular project was unique as it did not just attempt to measure 'behaviour', 'character' or other broad traits of the human personality, it actually attempted to measure the central component of unconscious thought in the early stages of infancy. It attempted to measure the very core of subjectivity, the essence of individual thought as it developed from the early stages of life. The measurement of 'autism' within a total population was an exceptional undertaking, and thus it received much attention and went on to form the basis of a global definition. 
In fact, other Maudsley researchers were already starting to dabble in the use of statistical and epidemiological studies in order to identify psychological states in childhood. In 1958, following the publication of the Percy Report, the Unit for Research in Occupational Adaptation at the Institute of Psychiatry was renamed the Social Psychiatry Research Unit. The idea of 'social psychiatry' was based loosely on McDougall's 1908 model of 'social psychology', although it also drew from a growing interest in therapeutic communities and the use of 'society' to treat mental health problems, as discussed in the work of Maxwell Jones, in the wake of the 1959 Mental Health Act. ${ }^{79}$ The Social Psychiatry Research Unit came to serve as the bureaucratic hub for psychological population studies. Some of the first studies carried out at the unit were conducted on children who would have previously been institutionalised. In 1960, Jack Tizard conducted two comprehensive surveys on the prevalence of 'mental subnormality' in children in the London and Middlesex areas, although these were primarily administrative surveys and were not presented as 'epidemiological studies'. As Tizard put it, 'we know the size of the administrative problem. ${ }^{80}$ The child population of Middlesex was then 213,945 and the number of children classified as 'idiots' and 'imbeciles' or 'severely subnormal' was 738 . This gave a prevalence rate of 3.45 per $1,000 .{ }^{81}$ This prevalence rate was almost identical to the figure obtained by the Ministry of Health in their count of all patients in psychiatric beds following the Percy Report. The Minister of Health, Enoch Powell, reported this in 1961 as 3.4 per $1,000 .^{82}$

In the early 1960s, several child psychiatrists at the Maudsley were becoming interested in the idea of conducting large-scale total population studies, for administrative as well as epidemiological purposes. One person who was particularly interested in this model of research in the 1960s was Michael Rutter. Rutter had studied under both Aubrey Lewis and Hans Eysenck at the Maudsley and also under Ben Pasamanick in New York. ${ }^{83}$ Pasamanick was a psychiatric epidemiologist who was interested in using epidemiological methods to determine causation and Rutter sought to expand this methodological approach to the field of child psychiatry ${ }^{84}$ In May 1965 Rutter was appointed as Senior Lecturer in Child Psychiatry, filling the post that had been left vacant since Anthony's departure in $1958 .{ }^{85} \mathrm{He}$ would later publish a manifesto arguing for the classification of all childhood 
psychiatric disorders, ${ }^{86}$ and also worked closely with the WHO in developing a multi-axial system of psychiatric diagnoses. ${ }^{87}$

In 1964, an Epidemiology of Mental Disorders Committee was established under the Medical Research Council (MRC). Jack Tizard and Michael Rutter served on the subcommittee exploring the need for child psychiatry services. They were scathing in their criticisms of the Underwood Report, which had claimed that it was impossible to forecast' the services required for 'maladjusted' children. ${ }^{88}$ Rutter, Tizard and the new psychological epidemiologists at the Institute of Psychiatry argued that this was a ludicrous claim because psychiatric epidemiology could measure rates very precisely. They claimed that 'within a year or two it should be possible to give a much more accurate picture of the prevalence of neuroses and psychoses in children, and of the medical, educational and social services required to deal with them ... epidemiological work in this field is today perfectly feasible. ${ }^{89}$ In Camberwell, a register of psychiatric morbidity had been established through a major collaboration between the Maudsley's Social Psychiatry Research Unit, the Ministry of Health and the local health authority, and this was providing the basis for a revolution in the measurement of psychological conditions. ${ }^{90}$ They argued that 'efficient screening techniques can be devised' and that 'diagnosis - by type of disorder and by severity - can be made reliable', and claimed that if investigators 'follow the standard procedures of epidemiological study' then 'the results are very satisfactory.9 ${ }^{91}$ Most importantly, they argued that an epidemiological study of autism was under way that was going to revolutionise service planning.

In fact, in the early 1960s, Rutter had conducted a small-scale study on the rate of 'autism' and other rare psychiatric conditions with a colleague in Aberdeen. However, Rutter was not at that point wholly convinced that autism could be measured, given the imprecision of the term, and he even placed 'autism' in inverted commas in his publication of the data. ${ }^{92}$ However, the debates on psychiatric epidemiology inspired him and Tizard to take on an even larger project in the measurement of the total child psyche. Thus, in 1964, he embarked on a major survey of all 'medical, behavioural, educational and other handicaps' in a total population of children living on the Isle of Wight, in collaboration with Kingsley Whitmore, the Senior Medical Officer of the Department of Education and Science. With this study, Rutter and Tizard sought to radically rethink the provision of special educational 
services in the whole of the UK, and they managed to persuade Whitmore to collaborate with them in doing so. By the mid-1960s, confidence was growing amongst government officials and research bodies, such as the MRC, that psychiatric epidemiology was a viable tool that could be used to plan services for exceptional groups who required unique forms of specialist help.

It was in this spirit of general optimism over the precise measurement of psychiatric conditions that the first full epidemiological study of autism, as a clearly definable, measureable entity, was conducted. There was nothing naive about this new approach to child development. One of Lotter's supervisors, Neil O'Connor, had studied philosophy and experimental psychology at Oxford, later moving to the Institute of Psychiatry to study the educational capacity and employability of 'defectives' with Tizard. He was a self-proclaimed communist and was committed to developing new approaches to social inclusion. ${ }^{93}$ Under O'Connor and John Wing's supervision, the young researcher, Lotter, was confident and steadfast in his approach to defining and measuring 'autism', and forged ahead with his study with remarkable determination, conviction and persuasion.

Dismissing the entire history of psychiatry and the description of infantile thought, Lotter proclaimed that 'autism' was entirely knowable and entirely measureable. Creak's committee had claimed that it was 'impossible' to use purely behavioural criteria 'if we were to convey what we all felt to be the heart of the matter - namely the presence of an impaired capacity for human relationships. ${ }^{94}$ However, Lotter argued that clear-cut, purely behaviouristic criteria were paramount to the development of reliable research on 'autism', regardless of the fact that the psychological state that was being described concerned the capacity to relate to others. Lotter drew his definition from Creak's, but discarded the category of 'apparent unawareness of his own personal identity' and subsumed it within other behavioural measures. $\mathrm{He}$ also replaced the presence of 'islets of ability' with objective test scores (Figure 4). Lotter surveyed all children in the Middlesex area aged between eight and ten years in order to generate a percentage figure for the rate of 'autism' in the general population of Britain and eventually to lead to new hypotheses on causation. ${ }^{95} \mathrm{He}$ developed a list of statements that were used to identify children with autistic conditions. This form was issued to teachers of 76,388 children between the ages of eight 


\begin{tabular}{|c|c|c|c|}
\hline \multirow[b]{3}{*}{ Item Behaviour range } & \multicolumn{3}{|c|}{$\begin{array}{c}\text { Mean percentage numbers and } \\
\text { types of children }\end{array}$} \\
\hline & \multicolumn{2}{|c|}{ Autistic } & \multirow{2}{*}{$\begin{array}{c}\text { Non-autistic } \\
\text { Group C } \\
(\mathrm{N}=22)\end{array}$} \\
\hline & $\begin{array}{l}\text { Group A } \\
(\mathrm{N}=15)\end{array}$ & $\begin{array}{l}\text { Group B } \\
(\mathrm{N}=17)\end{array}$ & \\
\hline All speech items* & 54 & 38 & 12 \\
\hline $\begin{array}{l}\text { 1. Speech not used } \\
\text { for communication }\end{array}$ & 63 & 33 & 0 \\
\hline 2. Reversal of pronouns & 21 & 12 & 8 \\
\hline 3. Echolalia & 67 & 46 & 25 \\
\hline 4. Repetition of phrases & 67 & 53 & 13 \\
\hline All social behaviour items & 72 & 53 & 14 \\
\hline 5. Visual avoidance & 53 & 58 & 2 \\
\hline 6. Solitary & 97 & 70 & 18 \\
\hline 7. Ignores children & 87 & 79 & 15 \\
\hline 8. Aloof and distant & 97 & 70 & 18 \\
\hline $\begin{array}{l}\text { 9. Walks/looks through } \\
\text { people }\end{array}$ & 30 & 6 & 0 \\
\hline All movement peculiarity items & 40 & 38 & 8 \\
\hline 10. Self-spinning & 47 & 14 & 0 \\
\hline 11. Jumping & 43 & 11 & 14 \\
\hline 12. Flapping & 33 & 14 & 14 \\
\hline 13. Toe walking & 13 & 18 & 9 \\
\hline $\begin{array}{l}\text { 14. Other marked } \\
\text { mannerisms }\end{array}$ & 63 & 47 & 5 \\
\hline All 'auditory' items & 45 & 34 & 10 \\
\hline 15. Behaves as if deaf & 67 & 50 & 5 \\
\hline 16. Covers ears & 17 & 26 & 11 \\
\hline 17. Distress at noise & 23 & 26 & 14 \\
\hline All repetitive/ritualistic items & 49 & 16 & 7 \\
\hline 18. Elaborate food fads & 27 & 6 & 2 \\
\hline
\end{tabular}

Figure 4 Table, 'Mean percentage scores on 24 behaviour items', from Victor Lotter, 'Epidemiology of autistic conditions in young children', Social Psychiatry 1, no. 3 (1966) 


\begin{tabular}{|c|c|c|c|}
\hline \multirow[b]{3}{*}{ Item Behaviour range } & \multicolumn{3}{|c|}{$\begin{array}{c}\text { Mean percentage numbers and } \\
\text { types of children }\end{array}$} \\
\hline & \multicolumn{2}{|c|}{ Autistic } & \multirow{2}{*}{$\begin{array}{c}\text { Non-autistic } \\
\text { Group C } \\
(\mathrm{N}=22)\end{array}$} \\
\hline & $\begin{array}{l}\text { Group A } \\
(\mathrm{N}=15)\end{array}$ & $\begin{array}{l}\text { Group B } \\
(\mathrm{N}=17)\end{array}$ & \\
\hline $\begin{array}{l}\text { 19. Lines and patterns with } \\
\text { objects }\end{array}$ & 43 & 9 & 0 \\
\hline 20. Spinning objects & 17 & 9 & 5 \\
\hline 21. Other elaborate ritual play & 83 & 35 & 11 \\
\hline $\begin{array}{l}\text { 22. Carrying, banging, twirl- } \\
\text { ing etc. objects }\end{array}$ & 37 & 38 & 9 \\
\hline $\begin{array}{l}\text { 23. Insistence on } \\
\text { sameness (objects) }\end{array}$ & 53 & 9 & 15 \\
\hline $\begin{array}{l}\text { 24. Insistence on } \\
\text { sameness (events) }\end{array}$ & 80 & 12 & 9 \\
\hline
\end{tabular}

Figure 4 (cont.)

and ten attending schools in the Middlesex area. Children identified by teachers were then further assessed to confirm their autism. Lotter reported the prevalence rate to be 4.5 per 10,000 of the population. ${ }^{96}$

Lotter claimed that he had developed 'adequate behavioural descriptions' for the condition of autism. These descriptions would encapsulate the symptom of autism, which he understood as a behavioural parameter and not a disease entity. As he put it:

the adjective 'autistic' was used in this study as a convenient descriptive label. It is important to note that the term was not intended to refer only to Kanner's syndrome of 'infantile autism', and in what follows is used without qualification to refer to all children who met the behaviouristic criteria used to select cases. References to 'autistic behaviour' are to be similarly interpreted..$^{97}$

Lotter's study was hence a quantification of the description of 'the autistic' within a total population. The requirement for 'precise behavioural criteria', which epidemiological studies demanded, encouraged 
new perspectives and descriptions of autism. The original 'autism' that had developed as the backdrop to theories on the role of instinctive drives in the formation of relationships, and which had been dominant in developmental psychology and psychoanalytic writings up until the 1950s, was anathema to psychiatric epidemiology. And yet, psychiatric epidemiologists were desperate to measure and quantify 'autism' because it was the only way that they could present a legitimate model to the government to champion the rights of 'autistic' children to be educated. Lotter's study, which bypassed the depth of conceptual problems associated with this, was gold dust to every parent or special educator who needed proof that an individual child had a right to be accepted, acknowledged and educated. It thus became fundamental to the construction of a new model of children's rights that incorporated all children, no matter what behaviour they displayed.

In developing ways to quantify and to measure autism, Lotter and the new autism psychologists necessarily redefined the concept of autism. Instead of measuring child development and its anomalies via theoretical models of an individual child's successive attempts to engage with reality through their relationships with people and objects, as in the Kleinian and Piagetian model, these studies measured child development and its anomalies as behavioural variables within a total population that represented the norm. The study of human relationships was not written out of this model because human relationships could still be observed as phenomena. However, questions about how, why or when relationships became pathological, particularly those concerning the child's capacity to imagine, hallucinate or fantasise about others, were absent from this new theoretical model.

When Lotter's study was finally published, it quelled the growing frustration amongst government officials about how to manage psychological disorders in children by providing a figure for the government to work with. Once this figure was available, the possibility of treating and educating these children became a reality. ${ }^{98}$ Lotter's epidemiological study offered new possibilities for the analysis of children's developmental and psychological problems using socialpsychiatric methods. Drawing from childhood psychosis research, it established autism, the major symptom of childhood psychosis, as a label that could be used in the rapidly changing landscape of mental 
health care for children. This label has stuck precisely because it provided security and certainty to parents, bureaucrats, psychiatrists, social scientists and others who witnessed the changes brought about by the Mental Health Act 1959.

Following publicity campaigns by SAC, Lotter's epidemiological study was reported in ten national newspapers, which increased public awareness of the condition..$^{99}$ In light of the media airtime granted to psychoanalytic popularisers, such as Winnicott and Bowlby, this kind of coverage was crucial to reformulating ideas of autism and children's rights. At a Department of Education and Science meeting in 1966, it was proposed that around 300-400 teachers would be required to teach autistic children. Courses at the Institute of Education and Birmingham University could be adapted 'to cater for the needs of psychotic children.' ${ }^{100}$ Tizard was to be consulted on this. Even though it was still sometimes called 'childhood psychosis', autism was finally achieving recognition at government level. Although, in 1968, the newly formed Department for Education and Science still refused to recognise autism as a specific handicap, they suggested that small educational units and parental guidance should be provided to all children with 'severe learning and developmental problems. ${ }^{\text {'01 }}$ Lotter had not fully convinced the government to adopt this label, but he had set in motion huge changes in the construction of children's rights as increasing numbers of people began to use the autism diagnosis as a way to prove that a child was not 'subnormal' or 'ineducable' and that they should be granted legal rights and entitlements to education, welfare and social support just like any other child.

\section{What is 'intelligence' anyway?}

As described in the first half of this book, the construction of psychology, and the social model it supported up until the end of the 1950s, was strongly associated with models for the measurement of 'intelligence' and 'intellectual ability'. As Wooldridge, Sutherland and others have pointed out, intelligence was the cornerstone of the development of psychology from the early twentieth century, and it was especially important in the field of experimental psychology and the development of tests for mental capacity. ${ }^{102}$ In fact, it was so dominant that, 
until the 1950s, there was no theory of mental capacity other than that of intelligence. However, the first attempts to quantify autism in the 1960s saw the first attempts to develop systematic tests for the measurement of other kinds of mental capacity that challenged and critiqued the supreme dominance of the intelligence test. These tests supported the new model of autism that was being assembled in the 1960s and were critical to its ascendency as it worked to challenge theories of children's inability to be educated.

Early psychological tests for autism focused on the measurement of sense perception, that is, the ability to 'sense' the environment and to perceive the external world. These differed from intelligence tests in that they focused on the finer points of sense perception and the way that these perceptions enabled individuals to form different models of the external world that were not necessarily related to their intellectual capacity. In fact, these tests were often pitted against IQ tests in order to show that some children could 'sense' the world around them, yet still could not develop concepts in relation to those perceptions. On the other hand, some children could not 'sense' the external world in the first place and this was why they could not develop concepts and the capacity to think. The latter were those considered to be 'psychotic' and 'autistic'. In other words, these tests explored the finer points of distinguishing between children who had previously been labelled 'mentally defective', 'subnormal' and 'psychotic'. They also provided the basis of a new model for testing subjectivity. Unlike mere behavioural criteria, these tests also enabled the formulation of new psychological theories on child development.

The application of tests to specifically identify 'autistic' children in Britain began in the 1960s with Beate Hermelin and Neil O'Connor's tests for pattern detection. Beate Hermelin was a German-born artist who studied psychology as a mature student at the University of Reading, before working on her $\mathrm{PhD}$ with Neil O'Connor on 'Concept Learning and Verbalisation in Imbeciles' in $1958 .{ }^{103}$ They were both part of the new generation of epidemiological and experimental psychologists, largely inspired by Tizard, who thought seriously about the psychology of 'defective' children, broadly defined. Instead of focusing on AngloAmerican models of child development, Hermelin and O'Connor cast their nets wider to encompass theories drawn from experimental psychologists internationally. In the early 1960s, O'Connor edited a 
volume on Recent Soviet Psychology, introducing British researchers to articles from the journal Voprosy psikhologii (Issues Relevant to Psychology), which had been established in 1955 and featured work by A. V. Zaporozhets, amongst others. Zaporozhets was a student of the controversial Soviet psychologist Lev Vygotsky and was interested in the development of conscious control of movements in infants and children. ${ }^{104}$ Hermelin and O'Connor were interested in his work on tracking the development of sensory functions. Herb Birch had written on the way the visual sense became established in children and how it influenced the child's ability to recognise words. These writers seemed more relevant to those interested in 'defective' children as they offered explanations for psychological abnormalities based on defective senses rather than psychogenic causes. Anthony had argued that childhood 'psychosis' was characterised by an infant's inability to process sensory information. Similar theories had also been put forward by William Goldfarb, who claimed schizophrenic children had a 'receptor dominance' for 'proximal' over 'distance' stimuli, resulting in a preference to touch, smell or lick, rather than look and listen. ${ }^{105}$ However, the details and causes of this inability had not been probed through the application of psychological testing materials and the quantification of the issue.

Hermelin and O'Connor's work did not primarily seek to challenge psychoanalytic models of autism, but rather sought to challenge theories of intellectual development that did not pay enough attention to the role that sense perception played in the formation of cognitive structures. In fact, Hermelin and O'Connor's work on subnormality had already tried to problematise and expand discussions on what human 'intelligence' really was by demonstrating that, if the specific sensory capacities of an individual's nervous system and the specific cognitive structure of their mind were understood, then special educational measures could be put in place to enable them to learn. The extent to which Hermelin and O'Connor's work was challenging general theories of intelligence was pointed out by one North American reviewer who suggested that their 1963 book, Speech and Thought in Severe Subnormality, should be renamed 'IQ isn't all' or 'intelligence isn't everything' because it demonstrated the many ways through which speech and thought could develop. ${ }^{106}$ It was this interest in the processes of learning that inspired them to develop a range of testing methods and materials. These included experiments for visual-motor reaction time, 
tactile and visual discrimination, auditory discrimination, transfer of training skills, generalisation of information and the psychological 'coding' of information using different modes or senses. They employed techniques such as galvanic skin conductance, electroencephalogram (EEG) recordings, heart-rate measures and systematic observation and recording methods in order to test for these. ${ }^{107}$

One key contributor who was instrumental in developing these tests was a psychologist named Peter Venables. He had studied skin resistance changes in industrial workers for his $\mathrm{PhD}$ thesis at the Social Psychiatry Research Unit, using an amplifier he had designed himself based on his knowledge of wartime radar. There was a growing interest in methods for measuring psychological activity using the techniques of biochemistry, physical chemistry and electronics in this period, leading to the establishment of the Society for Psychophysiological Research in $1960 .{ }^{108}$ Venables was a pioneer in the field, with his work on standardisation of method and nomenclature being adopted internationally. ${ }^{109} \mathrm{He}$ often collaborated with Hermelin and O'Connor in developing these techniques.

When Hermelin and O'Connor began to develop psychological tests to identify autistic children, they were interested in understanding the infant's ability to grasp reality, not in an abstract way that concerned their ability to form an ego and to understand their relationships to other people, but rather through the development of the infant's sensory systems and modes of perception. The 1959 Mental Health Act had expanded the testable child population, in particular enabling comparisons between 'subnormal' and 'autistic' groups. In the early 1960s, Hermelin and O'Connor worked with staff at Botley's Park Hospital in Chertsey and St Lawrence's Hospital in Caterham to select 'ten autistic and ten undisturbed, severely subnormal' children. In the same year, they collaborated with Brian Kirman from the Fountain Hospital, and would later collaborate with Sybil Elgar and others running the first schools specifically for autistic children. ${ }^{110}$

In their first 'sensory input' study, all children were matched for IQ levels using non-verbal tests such as the Seguin Form Boards, in which children had to place geometric shapes into their corresponding recesses. 'Autism' was then identified by child psychiatrists and was distinguished from simple 'subnormality' by the presence of at least three of Creak's nine points for 'autism'. In the test, children were rewarded if 
they gave correct responses to tactile, auditory and visual stimulation. They argued that 'autistic' children were more likely to respond to tactile and visual stimulation than auditory stimulation, although they could be taught to respond to sound if they were rewarded. ${ }^{111}$ In grasping for a larger theoretical framework through which to understand this phenomenon, Hermelin and O'Connor suggested that the developmental process in all infants was driven by a 'hierarchical structure of sensory systems'. At first, an infant responded to 'interoceptive and visceral sensations' and these were later superseded by a dominance of tactile and kinaesthetic sensations. Finally, the auditory and visual sensory systems became dominant. These developments were paralleled by the integration of different sensory information' in order that 'stimuli to one sense can be readily recognised and interpreted in another'. It was argued that 'autistic' children did not find it hard to learn new response patterns to auditory and visual stimulation, but rather found it difficult to inhibit earlier, more primitive responses. Hermelin and O'Connor argued that autistic children developed a spontaneous preference for tactile and visual stimuli and found it difficult to renounce this preference when presented with auditory stimulation. This distinguished them from their subnormal controls who did not have any sensory preferences, though they still found it difficult to learn. ${ }^{112}$ These tests appeared to provide psychological proof that 'autistic' children remained stuck in early stages of development in a way that was unique and not related to intelligence.

Hermelin and O'Connor later began to focus on the precise processes that children engaged in when learning from tactile, acoustic and visual stimuli. In their study of visual stimuli, they studied the eye movements of 'autistic' children when presented with images of different coloured cards or a human face that they viewed inside a small box. Sliding between the concepts of autism and psychosis, a typical phenomenon of the time, they argued that 'psychotic' children showed a 'longer time in undirected gazing' than 'subnormals' or 'normals', speculating that perhaps 'central fixation on a visual stimulus yields less information to psychotic children than to others.' ${ }^{13}$ O'Connor suggested that it was the 'short visual inspection time' of autistic children that 'handicapped' them in their daily life and their ability to learn. ${ }^{114}$ When it came to measuring auditory perception, they explored the 'psychotic' or 'autistic' child's ability to recall sequences of words. These tests determined that 'psychotic' children found it just as easy to remember a random 


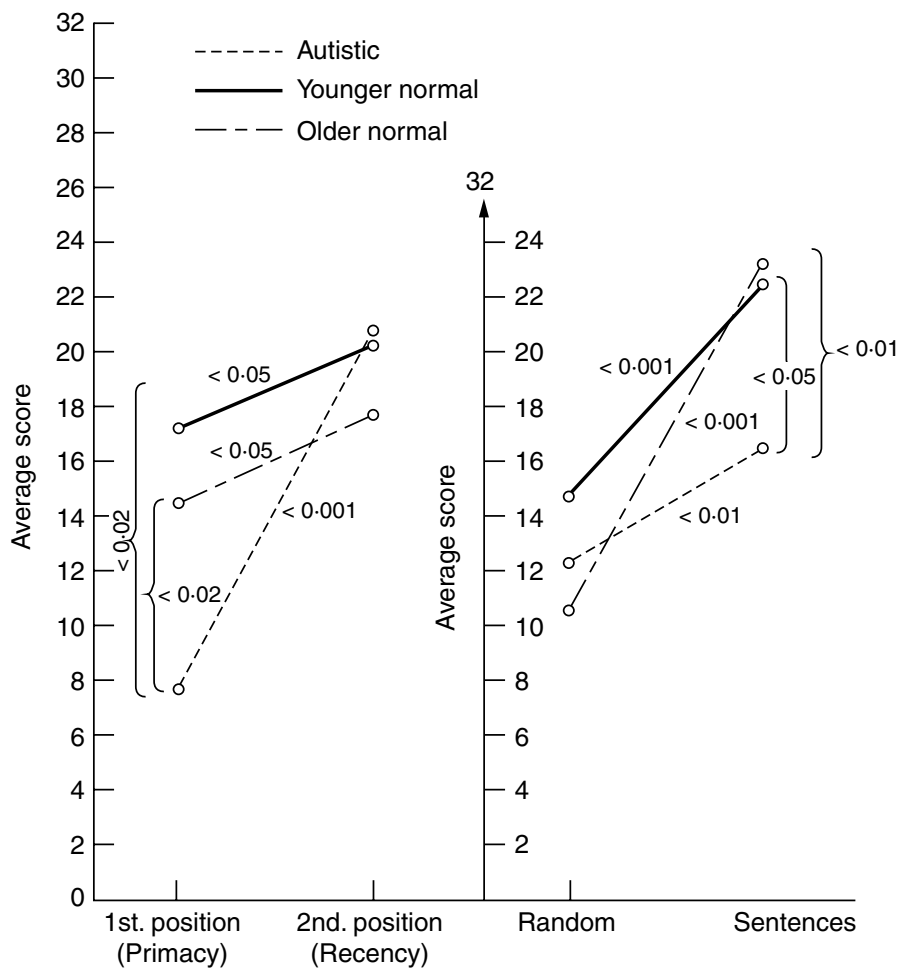

Figure 5 Graph comparing verbal coding ability in 'normal' and 'autistic' children, from B. Hermelin and N. O'Connor, Psychological Experiments with Autistic Children (Oxford: Pergamon, 1970)

sequence of words, such as 'glass hand cow pot cup meat spoon place', as they did a grammatical sentence. This differed from 'subnormal' and 'normal' children, who were more likely to remember grammatical sentences by sequential probability or to group random words according to concept. ${ }^{115}$ Placing this into a developmental theory based on language progression in 'normal' versus 'autistic' children, Hermelin suggested that this was because 'autistic children tend to "read back" words more exclusively from an immediate memory store than do the normals'. Autistic children showed particular 'deficits in verbal coding and patterning' that were unique to this group (Figure 5). ${ }^{116}$ 
Although much of Hermelin and O'Connor's work focused on sensory impairments in order to understand how autistic children developed intellectual capacity, they also conducted experiments to try to understand how sensory impairments may impact on a child's development of relationships and emotional attachments. One experiment, for example, sought to emulate experiments conducted by Harry Harlow. Harlow's famous experiments to test Bowlby's theory of attachment using rhesus monkeys had constructed cloth and wire 'mother' statues as substitutes for real monkey mothers in order to test the importance of the mother and child bond to later attachments. Without soft cloth, Harlow's infant monkeys often died, and even when raised with cloth and wire doll 'mothers', they later developed into disturbed adult monkeys. ${ }^{117}$ Hermelin and O'Connor tried to compete with attachment theorists and replicate this powerful cultural fable in order to generate a different story about autistic children. In one experiment, their aim was to measure different children's responses to isolated stimuli, such as rocking, softness, hardness and human contact. As these were human experiments, they thankfully did not emulate the extreme deprivation that Harlow's monkeys were subjected to and instead tested their 'autistic' and 'subnormal' children for five-minute bursts over the course of a day. What they found was that, after a long day of experiments, autistic children were just as likely to respond to real-life adults as 'subnormal' children, and that all the children treated a soft cloth (designed to represent the comfort of softness) and rocking platform (designed to represent the comfort of movement) in the same way as they did a box. There was very little that they could infer from such results, other than the fact that 'autistic children of this [low] intelligence level respond positively to an adult', which appeared to contradict the theory that autistic children shunned human contact. They realised their limitations, pointing out that the autistic children had in fact been more rational than they had been when the experiments were being planned. ${ }^{118}$ Nevertheless, they hypothesised that perhaps autism was not defined by a 'lack of interest in human or social contacts', but rather by 'more marked and extensive central nervous system anomalies' in a similar way to subnormality. It only developed as a problem with human relationships over time. ${ }^{119}$

By the mid-1960s, Hermelin, O'Connor and the new autism psychologists consistently presented the view that autism was a kind of 
sensory impairment that prevented the infant or child from developing emotional attachments. Writing on 'diagnosis, epidemiology, aetiology' in 1966, John Wing argued that the autistic child's problems were similar to those of deaf and blind children. As he put it: 'Autistic children are not totally deprived ... but their basic disability may be analogous to the deaf/blind child in that they are unable, at first, to make meaningful patterns out of sensory stimuli, whether auditory or visual. ${ }^{\prime 20}$ The child may shun social contact in the form of 'visual avoidance' because he or she 'often tries to avoid complex visual patterns (the most complicated of which is a human being).'121 They may also engage in 'auditory avoidance' because of their 'difficulty in making use of auditory information'. This, in turn, led to speech disorders or lack of speech. The 'behavioural abnormalities' and 'affective disturbance' were all symptoms of this primary impairment and could vary widely amongst children depending on 'the severity of the perceptual and speech disorders' and the 'suitability of the environment.' ${ }^{122}$ Taking the analogy further, John Wing pointed out that the epidemiological figures for autistic children were broadly analogous with those for blind and deaf children. Using Lotter's survey as a benchmark, he calculated 1,400 'autistic' children in England and Wales, an identical figure to the 1,400 blind children listed by the Department of Education and Science in $1962 .{ }^{123}$ It was clear that the new autism psychologists wanted the autistic impairment to be recognised on a par with other perceptual impairments.

Hermelin and O'Connor's tests were readily being employed to generate a considerable critique of general intelligence tests as the true measure of psychology. Writing in 1966, Peter Mittler, a lecturer in Developmental Psychology at Birkbeck, London, denounced the fact that general intelligence tests remained 'an important feature of the educational machinery in this country' even though they were wholly inadequate for testing all 'handicapped' children. He appreciated the development of the Merrill Palmer Scale because it could be flexibly applied in subsections and included non-verbal elements. ${ }^{124}$ Nevertheless, it still measured 'intelligence'. The Unit for Research in Occupational Adaptation had already challenged the idea of intelligence as a useful tool in social planning, demonstrating instead that all individuals had the potential to become social subjects, they just had varying levels of skills and capacity. The reincarnation of the unit as the Social Psychiatry Research Unit in 1958 only re-emphasised that all population 
groups could be measured, accounted for and enabled using new learning tools and techniques. The new autism psychologists were part of a new movement that was wholly against an elitist version of social mobility, as put forward by Cyril Burt and others, that linked intelligence to financial and social rewards. They were engendering a new model of society and social responsibility that did not rely on discriminatory models of intelligence and hierarchy. Instead they championed a model of society in which all individuals could contribute. They also championed the creation of new policies on education, employment rights, etc. to enable individuals to contribute, whatever their capability. As well as asserting total productivity, this model also asserted autonomy for all individuals regardless of their abilities, an aim that was strengthened via the 1959 Mental Health Act. The development of tests to identify 'autism' was one way to facilitate a new model of society.

The race was then on to develop accurate tests to measure the unique sensory impairments experienced by autistic children. The growth of the 'cognitive' movement in psychology meant that these sensory deficits were often explained in relation to the cognitive impairments that they engendered. ${ }^{125}$ One thing was clear, the new autism psychologists were united in the view that the condition was not caused by internal hallucinatory mechanisms associated with instinctive drives that affected emotional reactions, but was instead characterised by a sensory deficit that affected the child's ability to discriminate external images and sounds. Theories about dominant mothers were replaced with theories of 'sensory dominance' and the language of maternal deprivation was replaced with the language of sensory deficiencies and impairments. In this model, problems or difficulties in emotional development were regarded as a consequence of an infant's inability to " "make sense" of the world'. ${ }^{126}$

\section{The primacy of sense perceptions}

The 1960s witnessed a revived interest in questions highlighted by earlier developmental psychologists concerning the primacy of sense perceptions in the development of early thought. ${ }^{127}$ Progressive educators such as Maria Montessori had noted how frequently young children employed their tactual senses in order to explore 
objects. ${ }^{128}$ Furthermore, Piaget's work on the development of thought in children had highlighted the sensori-motor stage, in which infants grasped and manipulated objects in their attempts to conceptualise them. ${ }^{129}$ Experiments conducted by the North American psychologist Samuel Renshaw in the 1930s, as well as experiments at Zaporozhets' laboratory at the Moscow Institute of Psychology in the 1950s, had appeared to demonstrate the superiority of tactual-kinaesthetic over visual sensations in young children, and these were all well known in the 1960 s. ${ }^{130}$

However, in the mid-1960s, Hermelin and O'Connor and other developmental psychologists in both Britain and the USA began to challenge the idea that tactual-kinaesthetic senses were superior to visual perception in the development of early thought. This research had been stimulated by the integration of new 'defective' populations into the field of developmental psychology as well as a revived interest in William James' ideas of brain plasticity in the processes of learning. ${ }^{131}$ Herbert Pick and others from the University of Minnesota planned experiments of visual versus tactual shape sorting and matching to see which could be carried out prior to the other, arguing that visual perception was, in fact, important to infants from a very early age and that it preceded tactual discrimination in cognitive development. ${ }^{132}$ Richard Held at MIT sought to demonstrate that both tactualkinaesthetic and visual perceptions were completely dependent on each other when it came to the development of integrated behaviour in animals and humans. He devised a series of experiments with both humans and kittens in order to test 'plasticity in sensory-motor systems'. The most creative of these experiments involved the placement of two kittens inside a gondola with visual pattering on the inside. The exact spatial movements of one kitten were transmitted to a second kitten, which thus saw an identical visual display; however, the second kitten was not able to move its limbs freely and thus to correlate visual and motor information. As suspected, the second 'passive' kitten did not show normal physical responses to balls and other objects when leaving the gondola, whereas kitten number one readily held out its forepaws and avoided potential hazards. Held claimed that these experiments confirmed 'the sensory feedback accompanying movement-reafference plays a vital role in perceptual adaptation', and that motor movement assisted sensory awareness. ${ }^{133}$ These experiments also purported to 
show that visual cues and motor cues for behaviour were independent of one another.

In 1967, the MRC established a Developmental Psychology Unit under the directorship of Neil O'Connor. It was a small institution occupying the lower ground floor of a building on Euston Road in central London, and included 'a small laboratory with an electronic workshop bench' and a room with a 'two way screen' for child observation. None of the staff was medically qualified but all had a strong commitment to the principles of experimental psychology. At the MRC unit, the experimental study of autistic children became central to understanding wider problems within the science of developmental psychology. The unit brought together O'Connor, Hermelin, Venables and Uta Frith, who had conducted her PhD under O'Connor and Hermelin at the Institute of Psychiatry, focusing on visual pattern detection in autistic children. Venables' $\mathrm{PhD}$ students also worked there, along with a technical officer who provided transducers for recording signals, EEGs and skin resistance. The unit also had a strong connection to the Department of Psychology at University College London. ${ }^{134}$ The exploration of sense perception in the development of thought was central to many of the experimental methods developed there, in particular visual and aural senses. For example, one of Venables' PhD students, R. A. Hayes, conducted investigations into middle-ear function in autistic children to see whether problems in middle-ear muscles affected the ability to discriminate sounds and thus to understand speech. They hypothesised that this could also explain why autistic children showed heightened EEG-measured 'arousal' when subjected to continuous noise. ${ }^{135}$

Developing Hermelin and O'Connor's hypotheses, Frith argued that 'emotional disorders (withdrawal for instance) might be secondary to the severe difficulties in perceiving, thinking, understanding, and speaking. ${ }^{136}$ Frith would increasingly explain this in the language of cognitive sciences; for example, arguing that autistic children lacked 'complex perceptual tasks that depend on efficient information processing. Writing in 1969, Hermelin and Frith argued that 'The impairment might consist of a failure to make use of complex information from any one sense, or of a failure to integrate information coming from different sensory channels. ${ }^{137}$ One of their classic experiments employed a series of jigsaw puzzles, which relied more or less heavily on visual or tactual cues for fitting the pieces together (Figure 6). Frith and Hermelin argued 


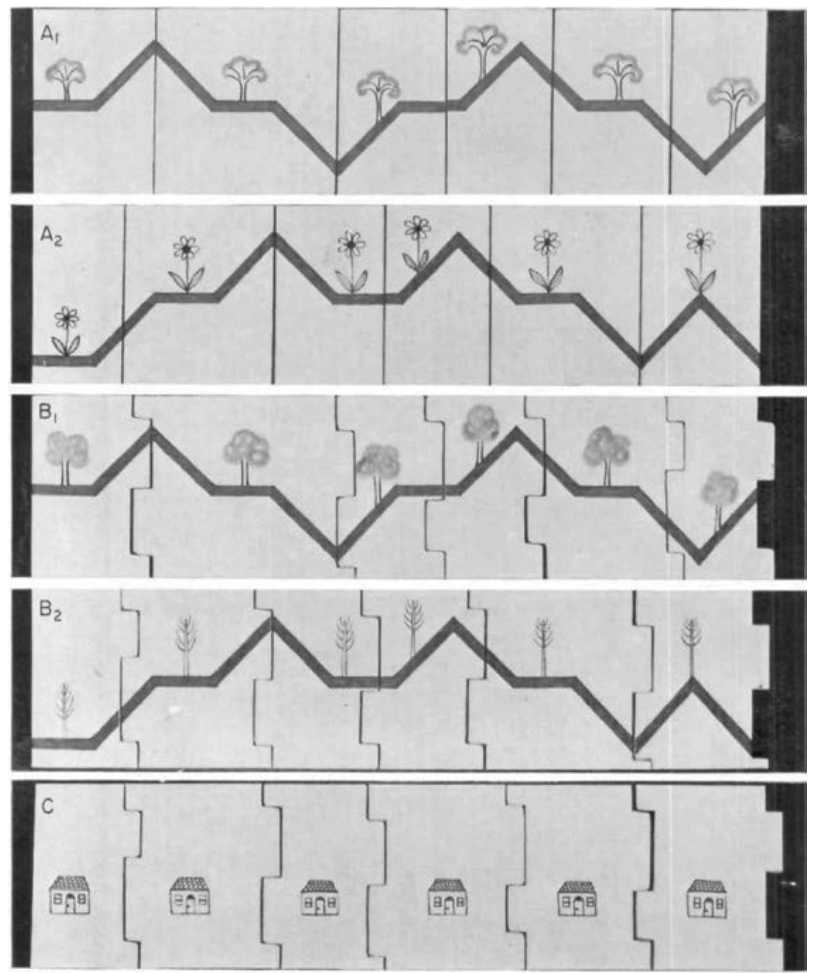

Figure 6 Uta Frith's early jigsaw tests for pattern detection, from U. Frith and B. Hermelin, 'The role of visual and motor cues for normal, subnormal and autistic children', J Child Psychol Psychiatry 10, no. 3 (1969)

that autistic children of low intelligence performed worst on the experiments that relied most heavily on visual cues, concluding that autistic children 'made relatively less efficient use of visual cues and relatively more of motor feedback than did other groups. ${ }^{138}$

Shifting their interest to language development, they asked, 'Can autistic children make sense of what they see and hear?', and employed different types of word 'recall' tests to see whether autistic children did not understand grammar, or whether it was the rules and patterns associated with grammar that they did not understand. Children in 
the autistic group failed to make use of either grammatical structures or other structures such as the use of repetitions or alterations in a sequence of words. They did not seem to apply logical rules in their reconstruction of language or in their reconstruction of patterned visual series of green, yellow and other coloured counters. Frith and Hermelin concluded that autistic children often reproduced patterns that were 'highly repetitive, predictable and rigidly structured', rather than extracting features from what they had heard or seen and then responding appropriately. ${ }^{139}$ Frith and Hermelin argued further that this inability to extract information and to respond appropriately extended even to the autistic child's behaviour. As they put it:

The stereotyped, rigid, ritualistic phenomena in the behaviour of autistic children might be regarded as an exaggerated form of pattern imposition. On the other hand, the unpredictable, often inappropriate, and seemingly random responses to environmental stimuli typical of autistic children may indicate an impairment in the feature-extracting process. ${ }^{140}$

Frith later developed more tests using xylophone sounds and rubber stamps to argue that autistic children did not increasingly adhere to rules as other 'normal' and 'subnormal' children did. Because early language acquisition is based on flexibility of rule application, autistic children had problems because they excessively followed simple rules and were unable to be flexible and abandon old rules when the situation required. ${ }^{141}$ All of these new ideas about autism were framed around the central claim that it was a kind of 'sensory impairment' similar to that seen in children with visual and hearing impairments.

\section{The central 'cognitive disorder' of autism}

In an international study group on infantile autism in 1970, a number of researchers put forward proposals for the central 'cognitive disorder' from which infantile autism developed. Drawing from Hermelin and O'Connor, J. A. M. Martin argued that the primary problem in autism was a failure of 'sensory organisation'. Martin had been testing the hearing responses of children diagnosed with autism and had found that they were unable to identify and recognise complex sounds. Although it was clear that such children could hear, it appeared that 
they were unable to bring this sense in accordance with other senses, thus suggesting 'imperfect multi-sensory integration. ${ }^{142}$ A similar view was put forward by Edward Ornitz of UCLA, although he expanded this, suggesting that 'the underlying disturbance may be a failure of the normal homeostatic balance between excitatory and inhibitory influences within the central nervous system', adding that 'this disturbance appears as a faulty modulation of motor output and sensory input. ${ }^{143}$

Lorna Wing conducted a comparison of the abilities of children with 'receptive or executive aphasia' and 'partial blindness' or 'deafness'. Her test results showed that the language and perceptual problems of autistic children resembled that of aphasic and partially blind/deaf children respectively. She argued that the existence of such 'specific handicaps' in autistic children meant that neurological and sensory handicaps must be causative of the condition and that therefore 'the "emotional withdrawal" hypothesis is completely untenable.. 144 Throughout the late 1960s, Lorna Wing promoted herself and her approach, helping to popularise her views. In 1969, she produced a leaflet for the Society for Autistic Children Children Apart: Autistic Children and Their Families, which was later published in the USA and also distributed internationally. Wing also published widely in women's magazines and public information leaflets, such as an article in Maternal and Child Care in 1967 stating that 'autistic children behave and respond to psychological tests, as if they cannot make a coherent pattern of the information which comes to them through their eyes and ears. ${ }^{145}$ Although these theorists took different standpoints on the exact form of the central sensory disorder that caused autism, they were all united in the view that the condition was not caused by emotional reactions or phantasies about relationships, but was instead characterised by a fixed deficit in certain aspects of thought. All of these theories had the potential to influence the mainstream education and treatment of autistic children at the start of the 1970s. Whoever could pinpoint and explain the precise cognitive problem, and develop tests for it, had the key to diagnosing autism.

At the biochemical level, many clinicians and researchers sought to identify the precise disturbances in metabolism that affected brain activity with a view to discovering genetic causes. By the mid-1960s, hospitals such as the Maudsley and Great Ormond Street would regularly send children for a series of biochemical tests. Children could be referred for full blood counts, insulin tolerance tests, urinary amino 
acid tests, X-rays of the wrist to detect bone age, X-rays of the skull, heart and lungs, and adrenocorticotropic (ACTH) stimulation to measure the response of the adrenal glands to stress. ${ }^{146}$ The child's head circumference, weight and height were also measured and EEG tests were carried out to measure electrical charges in his brain. ${ }^{147}$ In 1968, Brian Kirman, then consultant physician at the Maudsley and lecturer at the Institute of Psychiatry, published an article in the British Medical Journal urging all doctors to give full diagnostic assessments to mentally atypical children, including 'a biochemical screening for metabolic errors, examination of the urine for mucopolysaccharides, of the lymphocytes for inclusions or vacuoles, [and] possibly an EEG. ${ }^{148}$ The aim was to distinguish different problems within this large group of children and eventually to develop new treatments. Kirman had published work on 5-hydroxytryptamine (serotonin) levels in children with phenylketonuria and had a general interest in building on previous studies that had associated metabolic abnormalities with mental deficiency, such as Fagge's association between cretinism and absence of thyroid production. ${ }^{149} \mathrm{He}$ regarded autism as a form of retardation with probable organic cause. ${ }^{150}$ Reviewing the growing literature on autism in 1967, Kirman argued that autism was a form of mental retardation in which only certain intellectual functions could advance: 'It is probable that most patients who would have previously been described as "idiot savant" would now be classed as autistic.'151 Although none of this research provided any evidence that there was a unique biochemical disturbance that could be related directly to autism, it did help to support the idea that there may be a biochemical reason why 'autistic' children lacked abilities in sensory perception.

In the midst of whirlwind change concerning the conceptualisation of child development and with a lack of evidence regarding biochemical causation, psychological researchers in Britain began to focus wholeheartedly on the details of definition. It should be no surprise that the most vehement and passionate debates between psychologists should take place over the concept of autism. Because of its importance within a general theory of child development, autism had become a genuine battleground for the soul. The Maudsley group of autism psychologists, distinguished themselves within this fracas by focusing in precise detail on the development of psychological tests to identify autism; the use of epidemiology to rationalise and validate those tests; and ultimately the 
development of a genetic theory of autism. Their idea of what constituted scientific evidence was strongly secured in statistical techniques developed in the Galtonian tradition. They drew impressively upon this tradition in the construction of their arguments and this is why they ultimately received so much support. It is because of this that definitions of autism developed in Britain were widely dominant in the international literature.

By the early 1970s, the argument that autism was a problem in sense perception that led to cognitive impairments, which in turn led to emotional withdrawal, in precisely that order, was vying with psychoanalytic models that still relied heavily on descriptions of early phantasies involved in the formation of emotional attachments, and the potential role of mothers in disturbing these early fragile bonds. Discussions of sensory impairment then vied with descriptions of maternal deprivation in establishing a logic for the creation of autistic symptoms. The new autism psychologists argued that visual and aural sense perceptions were impaired in autistic children and this restricted their normal development. This highlighted the significance of these systems in all children's development, as well as helping to develop a new language for the description of autism that did not engage with psychoanalytic descriptions of infantile phantasies and the early development of unconscious mental life, nor with the role of mothers in affecting this. These approaches would become increasingly distanced in the 1970s, so that work such as that conducted by Anthony that fused psychoanalysis, developmental psychology and psychiatry was harder to sustain. From the psychoanalytic side, Winnicott, in particular, firmly drew the line between these approaches, claiming that a problem with the infant-mother bond could lead to an 'adaptive failure' in the child, causing autism. In 1966, he gave a paper to the Society for Autistic Children in Leicester in which he discussed his approach to some children he had treated and claimed that this validated his concern about maternal care and autism. ${ }^{152}$

In 1972, Frances Tustin, a child psychotherapist who was trained at the Tavistock Centre under Esther Bick, published her first book Autism and Childhood Psychosis, in which she put forward her theory of 'normal primary autism' where 'the infant is the stream of sensations from which constructs emerge as nameless entities. ${ }^{153}$ This, she claimed, was akin to what E. J. Anthony had called 'normal neo-natal solipsism', which 
was part of normal child development. Tustin was a critical voice in developing the original concept of autism in relation to infantile phantasy, but she was encountering growing obstacles placed by the new generation of autism psychologists. Tustin's theory of 'encapsulated' or 'regressive' secondary autism also developed Anthony's work, depicting a child with either 'hypersensitive responses to sensory stimuli' in 'encapsulated' autism or 'intolerance of bodily separateness' in the 'encapsulated' form. ${ }^{154}$ With regard to the issue of sensory impairment, she argued that although sensory impairments could stunt a child's development, thus leaving them in a state of autism, it was the psychological state of autism, associated with infantile phantasy, that was primary. She argued that it was to be expected that 'the sensory impediment of deafness is sometimes to be associated with autistic features', as was 'mental-defect and brain-damage', because 'impediments to taking in the outside world can mean that sensations in the child's own body remain of undue significance.' However, she maintained that the state of autism existed before sensory impairments and that autism should be understood as an internal emotional state associated with 'phantasies' and 'hallucination' that later became the mainstay of unconscious life. ${ }^{155}$ This came to the crux of what distinguished the approach of Tavistock human relations psychologists and the new autism psychologists. Even though the new autism psychologists were discussing the formation of atypical human relationships in autism, they were doing so in a way that did not engage with psychoanalytic models of phantasy and early unconscious life. Their new 'style of reasoning', based on measuring 'the autistic' within a population group, meant they began to forge new meanings for the concept. Their commitment to defining what was initially a description of subjective early unconscious life using objective measures from psychiatric epidemiology and experimental psychology led to a complete transformation in the meaning of autism.

\section{Goodbye phantasies: the disappearance of hallucinations}

By the early 1970s, epidemiological and experimental studies of autism by the new autism psychologists were pushing the limits of a human relations approach to developmental psychology. This highlighted the issue of whether or not autism was in fact associated with schizophrenic 
thinking, which had been a cornerstone of the original concept of autism and its theoretical application. The increasing establishment of child psychiatry as a unique discipline was also adding momentum to this question. In 1965, Wilfred Warren from the Maudsley served as Consultant Advisor in Child Psychiatry to the Ministry of Health, helping to plan child psychiatric services across England and Wales. ${ }^{156}$ $\mathrm{He}$ argued that children admitted as psychiatric inpatients should not be kept on the general paediatric wards, and that child psychiatrists should be managed under the health rather than the education authorities. ${ }^{157}$ The 1965-68 Royal Commission on Medical Education endorsed Maudsley principles and concluded that training in child psychiatry should constitute an essential part of any training in general psychiatry. In a paper presented to the Association for the Study of Medico-Education conference in the late 1960s, Rutter pointed out that advances made in child psychiatry in the fields of 'mental subnormality', 'cerebral palsy' and 'epilepsy' meant that child psychiatry could no longer be regarded as the poor cousin of adult psychiatry and that the discipline needed to open up to the reality that many adults with psychiatric disorders had developmental histories. ${ }^{158}$

In the late 1960s, Rutter and several colleagues at the Institute of Psychiatry decided to address the relationship between autism and adult schizophrenia by conducting a follow-up study of sixty-three children who had been seen at the Maudsley psychotic clinic in the 1950s and tracking their development. They compared their outcomes to those of sixty-three children who had not presented with any concerns in childhood and sought to discover how many of them went on to develop schizophrenia or hallucinatory experiences. Concerning the problem of hallucinatory phenomena, they ascertained that although 'several adolescent children continued to have childish fantasies' in followup, they 'all distinguished between reality and make-believe'. In addition, although a few of the children 'behaved in an odd manner which gave rise to the suspicion that they were having hallucinatory experiences ... in none was there convincing evidence of hallucinations, and no child with speech described sensations or happenings which were hallucinatory.' ${ }^{159}$

The possibility of hallucinations and phantasies in non-speaking autistic children was a moot point in the late 1960s following Lotter's work. Whilst on the one hand, Lotter could claim to have turned autism 
into a purely behavioural category, Creak and others still insisted that its relation to subjective development meant that it could never be a purely behavioural category. However, approaches in epidemiology and experimental psychology became increasingly standardised, and Hermelin, O'Connor and Frith's work challenged the idea that any mental processes could pre-exist sense perceptions, which, they argued, were primary in the development of infantile thought patterns. All this work was shifting the new autism psychologists away from the idea that autism was a subjective state characterised by a complex and creative fantasy life.

However, the most significant study that was conducted within these significant shifts was one developed in 1971 by Israel Kolvin, from the Nuffield Child Psychiatry Unit in Newcastle. This study initially sought to test Anthony's hypothesis that 'psychotic disorders in childhood are dependent on the age at which the process begins'. In order to do this, Kolvin separated childhood psychotics into groups relating to age of onset and then divided up the 'phenomenology' of the condition according to these different groups. What was significant in the planning of this exercise was the implementation of 'rigorous criteria' to ensure that the children could be compared with one another equally. As with other epidemiological models of autism, the rigorous quality of the data depended on its ability to be examined and then replicated by numerous researchers.

Kolvin argued that researchers should never attribute phantasies to children who did not have the words to describe these themselves. He explained his approach as follows: 'Both groups of psychotics were examined for hallucinatory phenomena ... Gazing round in a distracted manner or looking as if they were hearing voices were insufficient. In addition, at some time the child must have given an account of hallucinatory phenomena. ${ }^{160}$ These criteria were exceptionally rigorous - to the extent that they were narrowly conceived - when concerning infants and children who could not talk or had very limited language abilities. Nevertheless, they were regarded as essential to the progression of statistical methods in child psychiatry. Given the study design, it is perhaps unsurprising that Kolvin found that children with late-onset psychosis 'commonly hallucinated', whereas those with early-onset psychosis, in the first three years of life, were more likely to suffer from 'severe speech delay and many speech anomalies' as well as 'stereotyped movements' 
and 'poor relationships' rather than hallucinations. ${ }^{161}$ Kolvin's study excluded the possibility that autism in infants and young children was accompanied by hallucinatory thinking in any form. His description of autism was the direct opposite of that which had first been put forward by Bleuler and which had been supported by Creak, Klein and Anthony from the late 1920s to the 1960s. However, it is this model of 'earlyonset psychosis' that later became dominant in descriptions of the concept of 'autism. This is ironic because 'autism'. had originally been used precisely to describe ordinary early infantile thought.

In 1972, Kolvin argued that 'the subject of childhood hallucinations requires clarification' and that any account of a hallucinatory experience in childhood would have to include, at the very least, an account of its 'sensory modality', a description as to its intermittent or continuous type, an account of whether the child can appreciate its pathological nature, whether there is 'imagery' or 'pseudo hallucinations', the child's state of consciousness, and their psychological meaning. ${ }^{162}$ This developed work on sense perception by seeking to clarify the precise senses that infants were using to conceptualise objects and other people to make emotional connections. Again, clearly, it was not possible to give details on the sense modalities of hallucinations in infants and children without speech, and this poured more cold water on the concept of childhood schizophrenia and on theories of the visualisation of instinctive drives generally that had been dominant in psychoanalytic descriptions. In fact, Kleinian theory in particular had not clarified the sense modalities of early infantile hallucinatory thought, but had presented it as almost a whole body experience, and Bender and others had also followed such a model.

Kolvin's 1971 study was extremely influential and all researchers who followed his study design reached similar conclusions. ${ }^{163}$ In the 1970s, these researchers focused more and more on the study of language and increasingly regarded autism as a 'communication' disorder rather than a psychotic disorder. A 1972 quotation from Rutter summarises the uncertainty and, indeed, irony, surrounding the reversal in the meaning of autism that followed the introduction of statistical and epidemiological methods:

Autism means a withdrawal into fantasy but this is not what happens in the syndrome of autism. The schizophrenic may retreat from reality into 
fantasy, but the autistic child does not retreat, rather he fails to develop social relationships - a crucial distinction. Furthermore, so far as one can tell, the young autistic child has a deficiency of fantasy rather than an excess. ${ }^{164}$

Of course, what constituted 'convincing evidence' of the existence of hallucinations in children differed widely amongst practitioners. Whereas psychoanalytically influenced psychologists inferred hallucination from children's actions, Kolvin, Rutter and related researchers thought that this kind of inference should be eliminated from all research inquiries. This was not because they were averse to the idea of hallucinations in infants and children, but rather because such claims would have disrupted the accuracy of epidemiological and observational studies. In general, researchers would follow Kolvin and Rutter in claiming that unless a child described hallucinatory thoughts using speech, they could not be assumed to experience hallucinations. Whereas this contention would not eliminate the concept of hallucination in adult psychiatry, because linguistic descriptions of hallucination still counted as a form of behaviour, it completely transformed child psychiatry where infants and young children had no words to describe such events.

Highlighting the changes occasioned by the introduction of statistical and epidemiological methods, Rutter had argued in 1972 that 'the autistic child has a deficiency of fantasy rather than an excess', and in a 1978 article, he lamented the fact that 'childhood schizophrenia' had suggested a 'rich fantasy life', when in fact autism was characterised by a 'lack of imagination. ${ }^{165} \mathrm{He}$ was also frustrated by the fact that many child psychiatrists 'use childhood schizophrenia, autism, and child psychosis as interchangeable diagnoses', because this had further confused matters. ${ }^{166}$ Although his work had successfully cast off the ties of childhood hallucination theories, he had not been able to build an alternative foundation theory of the origins of human relationships as he focused on building statistical and social scientific methodologies.

As discussed in Part one, the 1940s and 1950s saw, human relations psychology, and the theories of childhood psychosis, schizophrenia, autoerotism, primary narcissism and autism within it, enter into a general discourse of child development and subjectivity that was popularised in relation to wider theories of maladjustment. Needless to say, the neglect of children with 'mental deficiency' or 'subnormality' within 
theories of the development of emotional stability and the formation of relationships was an obvious problem in the models of welfare provision that prevailed in the post-war period. However, the rumblings of discontent amongst parents who disagreed with the logic of professional psychologists, psychiatrists and social workers of the human relations school became louder and louder in the 1960s. The 1960s thus witnessed growing criticism of the expertise supposedly held by human relations and object-relations psychologists. This further sanctified the divide between professionals trained within the Tavistock and those trained in what was increasingly becoming a distinctive school of experimental psychology focused on the central issue of autism, dominated by psychologists based at the Maudsley and the Institute of Psychiatry. This led to a radical critique and overhaul of Tavistock human relations models of child development. In this overhaul, the core of all theories of psychological development - autism - was systematically pulled apart and reinvented.

What is important to remember, however, is that Rutter, Kolvin, Hermelin, O'Connor, Lotter, Frith and the Wings did not adopt a total behaviourist stance that disregarded the possibility of unconscious or preconscious mental processes. In the 1960s and 1970s, such an idea would have been untestable within the growing cognitive movement. ${ }^{167}$ Instead, they always promised the eventual revelation of the mental processes that lay behind the phenomenon of 'autism', the ultimate exposé of the hidden thinking processes that meant that some children did not develop language and relationships in the same way as others. The Wings and Lotter claimed that by calculating 'the autistic' in a population, it would eventually lead to a better definition and deeper understanding of the category; Hermelin, O'Connor and Frith argued that experimental psychology would reveal the specifics of sense perception in autistic children and the unique way that they developed conceptual maps that influenced their emotional life; Rutter and Kolvin thought that limiting the application of the concept of hallucination would clarify its form and validity within theories of developmental psychology. This promise of an eventual revelation supported further research and exploration using a model of autism that was stripped of its original meaning. This was a new version of 'autism' in which there was no phantasy, no hallucination, no unconscious, but merely the absence of thought and meaning where an entire edifice had once been built. In 
general, this strengthened all theories of childhood psychological disorder that were focused on a cognitive deficit or impairment model. It also strengthened all epidemiological and sociological work that promised to offer some details and explanations about these thinking processes, and to finally develop some psychological theories to replace those that had been based on instinctive drives and hallucinatory thinking. The 1970s and 1980s saw the first attempts to revivify the meaning of autism using new tools, ideas, methods and ideologies.

It was via the creation of these new models for measuring and managing autism that the meaning of the term 'autism' would undergo a radical transformation. By the 1970s, there was a complete reversal in the meaning of the word. From the 1920s to the 1960s, the term had been used by child psychiatrists and psychoanalysts in Britain and the USA to describe excessive hallucinations and phantasy in infants and children and was regarded as a subcategory of childhood schizophrenia. However, the new generation of epidemiological and experimental autism psychologists in Britain in the 1960s and 1970s transformed that meaning. Instead of employing the term to describe excessive hallucinations and a complex fantasy life, they began to use it consistently to describe a lack or deficiency of fantasy life. This transformation in the meaning of the term 'autism' was paralleled in Britain by further shifts in the institutional care and education of children considered to have mental abnormalities. This chapter has argued that after institutions for 'mentally defective' children were closed, many people thought it was no longer acceptable for child psychiatrists to speculate about the fantasy life and hallucinations of children and to view their problems as models for the psychiatric problems of adults. This was the start of a new discourse that emerged to describe the 'impairments' of autistic children. This previously highly-influential descriptive model for representing children's thoughts was disregarded in preference for statistical and experimental accuracy.

\section{Notes}

1 Schofield, Enoch Powell and the Making of Postcolonial Britain; Ward, British Culture and the End of Empire.

2 Savage, Identities and Social Change in Britain since 1940.

3 Marks, Sexual Chemistry. 
4 Thane and Evans, Sinners? Scroungers? Saints?.

5 Thomson, Lost Freedom.

6 Hansard, William Compton Carr, 18 May 1960.

7 Robert Holt and John Turner, Political Parties in Action.

8 Hansard, William Compton Carr, 18 May 1960.

9 K. Jones, A History of the Mental Health Services, p. 306.

10 K. Jones, A History of the Mental Health Services, p. 293.

11 K. Jones, A History of the Mental Health Services, p. 304.

12 Percy Report, 1957, paras 17-19, in Watkin, Documents on Health and Social Services 1834 to the Present Day, p. 387.

13 Percy Report, 1957, paras 17-19, in Watkin, Documents on Health and Social Services 1834 to the Present Day, p. 387.

14 Kushlik, 'Social problems of mental subnormality', p. 396.

15 Hilliard and Kirman, Mental Deficiency, p. 8.

16 Hilliard and Kirman, Mental Deficiency, p. 24; O'Connor and Tizard, The Social Problem of Mental Deficiency, pp. 33-34.

17 Hilliard and Kirman, Mental Deficiency.

18 Watkin, Documents on Health and Social Services 1834 to the Present Day, pp. 392-393.

19 Wilkin, Caring for the Mentally Handicapped Child.

20 Percy Report, 1957, paras 17-19, in Watkin, Documents on Health and Social Services 1834 to the Present Day, p. 389.

21 E.g. Hansard, HC Deb 6 May 1959 vol 605 cc 403-483.

22 MHA1959: Part 1, Section 4, p. 3; Section 3, p. 3.

23 MHA1959: Part 2, Section 10, p. 6.

24 MHA1959: Part 4, Sections 25 and 26, pp. 15-16.

25 Watkin, Documents on Health and Social Services 1834 to the Present Day, p. 393.

26 Kushlik, 'Social problems of mental subnormality'.

27 K. Jones, A History of the Mental Health Services, p. 316.

28 Bowtell, 'The historical background'.

29 Tizard and Grad, The Mentally Handicapped and Their Families.

30 National Archives (NA) NA/ED50/994: Special Educational Treatment Psychotic Autistic Children 1961-1965. Letter from P. Benner (MoH) to H. E. Clinkard (MoE), 27 August 1961.

31 NA/ED50/994: Special Educational Treatment Psychotic Autistic Children 1961-1965. Letter from P. Benner (MoH) to H. E. Clinkard (MoE), 27 August 1961. 
32 NA/ED50/994: Draft report of the SMHAC sent from Benner to Clinkard 6 September 1962.

33 NA/M.603(1)/61 (ED 50/789-792): Letter from H. E. Clinkard (MoE) to P. Benner (MoH), 21 June 1962.

34 NA/M.603(1)/61 (ED 50/789-792): Minutes of Meeting, 2 March 1962.

35 NA/M.603(1)/61 (ED 50/789-792): Minutes of Meeting, 16 March 1962.

36 NA/ED50/994: Special Educational Treatment Psychotic Autistic Children 1961-1965. Letter from P. Benner (MoH) to H. E. Clinkard (MoE), 6 September 1962.

37 Creak, 'Schizophrenic syndrome in childhood', 889.

38 Creak, 'Schizophrenic syndrome in childhood', 889-890.

39 Allison, 'Perspectives on a puzzle piece.'

40 Silverman, Understanding Autism.

41 Brugha et al., 'Contribution and legacy of John Wing, 1923-2010'.

42 NA/ED50/994: Wing Memorandum, p. 2.

43 NA/ED50/994: Wing Memorandum, p. 3.

44 NA/ED50/994: Wing Memorandum, p. 2.

45 NA/ED50/994: Wing Memorandum, p. 8.

46 NA/ED50/994: Wing Memorandum, p. 2.

47 NA/ED50/994: Wing Memorandum, pp. 2-3.

48 NA/ED50/994: Wing Memorandum, p. 10.

49 NA/ED50/994: Wing Memorandum, p. 10.

50 Tizard, 'Social psychiatry and mental subnormality', p. 59.

51 Tizard, 'Community services for the mentally subnormal', p. 133-134; Tizard, 'Results and summary of the Brooklands experiment'.

52 NA/BD18/1438: Appendices to Letter from M. J. Craft to Dr P. Alwyn Smith, 18 January 1965.

53 NA/ ED50/ 994: Draft BPS report 1966.

54 Neil O’Connor, 'Tizard, Jack (1919-1979)' Oxford Dictionary of National Biography. http://dx.doi.org/10.1093/ref:odnb/31764 Accessed 25th October 2016.

55 NA/ED50/969: Special Services: General Files, Society for Autistic Children 1964-1968, 'A memorandum to the Ministers of Health and Education on the diagnosis, education and treatment of autistic children' from the SAC, October 1963, p. 3.

56 NA/ED50/969: 'A memorandum to the Ministers of Health and Education on the diagnosis, education and treatment of autistic children' from the SAC, October 1963, p. 3. 
57 NA/ED50/969: 'A memorandum to the Ministers of Health and Education on the diagnosis, education and treatment of autistic children' from the SAC, October 1963, p. 4.

58 NA/ED50/969: 'Costs of running a day school for five autistic children'.

59 NA/ED50/969: SAC Memorandum on the Training of Teachers.

60 Mittler. 'Obituary: Stanley Segal' The Independent Saturday, 9th July (1994).

61 NA/ED50/969: SAC Memorandum on the Training of Teachers.

62 E.g. Ferster and DeMyer, 'The development of performances in autistic children'.

63 Isaacs et al., 'Application of operant conditioning to reinstate verbal behavior in mute psychotics'; Hayes, The Ape in Our House; Rheingold et al., 'Social conditioning of vocalisations in the infant'.

64 MHCP/A: 640995: Report, 14/12/65.

65 Lovaas, 'A program for the establishment of speech in psychotic children', p. 143.

66 Lovaas et al., 'Acquisition of imitative speech by schizophrenic children'; Lovaas et al., 'Building social behaviour in autistic children by use of electric shock'.

67 Bender et al., 'Treatment of autistic schizophrenic children with LSD-25 and UML-491'; Bender et al., 'The treatment of childhood schizophrenia with LSD and UML'.

68 Bender et al., 'Treatment of autistic schizophrenic children with LSD-25 and UML-491', 170; Abramson, 'The use of LSD (d-lysergic acid diethylamide) in the therapy of children'; Freedman et al., 'Autistic schizophrenic children'; Simmons et al., 'Modification of autistic behavior with LSD-25'.

69 NA/ED50/969: 'A Memorandum to the Ministers of Health and Education on the Diagnosis, Education and Treatment of Autistic Children' from the SAC, October 1963, p. 5.

70 NA/ED50/969: 'A Memorandum to the Ministers of Health and Education on the Diagnosis, Education and Treatment of Autistic Children' from the SAC, October 1963, p. 6.

71 Hansard, HC Deb 22 March 1963 vol 674 cc 912-922. William Compton Carr Autistic Children (Education and Training).

72 NA/ED50/969: Special Education Sub-committee Report, 28 January 1963, p. 1.

73 Hansard, Christopher Chataway: 'Autistic Children (Education and Training)', HC 22 March 1963; Report by the Ministry's Chief Medical Officer on the Health of the Schoolchild for 1960 and 1961. 
74 Hansard, Christopher Chataway, 'Autistic Children (Education and Training)', HC 22 March 1963.

75 NA/ED50/969: 'Meeting to discuss the provision for autistic children with representatives from the Society for Autistic Children, 23rd July, 1964'.

76 The findings were reported in Wilson, Administrative and Social Aspects.

77 Hayward, 'Medicine and the mind'.

78 Porter, The Rise of Statistical Thinking, 1820-1900; Hacking, The Taming of Chance.

79 McDougall, An Introduction to Social Psychology. On Wundt, see Hearnshaw, The Shaping of Modern Psychology, pp. 136-137; Shorter, A History of Psychiatry, pp. 229-238; M. Jones, Social Psychiatry; Bell and Spiegel, 'Social psychiatry', 337-338; Lunbeck, The Psychiatric Persuasion.

80 Tizard, 'Community services for the mentally subnormal'.

81 Tizard, 'Community services for the mentally subnormal'. Note, this study was conducted before the administrative integration of Middlesex into the Borough of London.

82 K. Jones, A History of the Mental Health Services, p. 339.

83 Rutter, 'The emergence of developmental psychopathology'.

84 Rutter, 'The emergence of developmental psychopathology'.

85 Institute of Psychiatry, Annual Report, 1964-1965.

86 Rutter, 'Classification and categorisation in child psychiatry', 71-73; Shaffer, 'Classification and categorisation revisited', pp. 108-110.

$87 \mathrm{MHCP} / \mathrm{A}$ : Item sheets.

88 Report of the Committee on Maladjusted Children (The Underwood Report), 1955.

89 MHCP/A: Rutter Files: Autism Research: MRC Epidemiology of Mental Disorders Committee: Sub-Committee on InPatient Accommodation for Mentally Ill and Seriously Maladjusted Children and Adolescents, c.1964, p. 5.

90 Hayward, 'Sadness in Camberwell'.

91 MHCP/A: Rutter Files: Autism Research: MRC Epidemiology of Mental Disorders Committee: Sub-Committee on InPatient Accommodation for Mentally Ill and Seriously Maladjusted Children and Adolescents, c.1964, p. 5.

92 Rutter, 'Schooling and the "autistic" child'.

93 Interview with Uta Frith, conducted by Bonnie Evans, 17 December 2014.

94 Creak, 'Schizophrenic syndrome in childhood', 889-890. 
95 J. K. Wing, 'Social treatments of mental illness', p. 27.

96 Lotter, 'Epidemiology of autistic conditions in young children'.

97 Lotter, 'Epidemiology of autistic conditions in young children', 125.

98 NA/ED50/994: Branch meeting with HM inspectors, 30 March 1966.

99 NA/ED50/969: Newsletter, SAC, March 1965.

100 NA/ED50/994: Branch meeting with HM inspectors, 30 March 1966.

101 NA/ED50/969: Minute Sheet concerning SAC, 1968.

102 Wooldridge, Measuring the Mind; Sutherland and Sharp, Ability, Merit and Measurement.

103 Hermelin, Concept Learning and Verbalisation in Imbeciles.

104 Holovinskyi, Psychology in Ukraine.

105 Goldfarb, 'Receptor preferences in schizophrenic children'.

106 Spradlin, 'Review of Speech and Thought in Severe Subnormality', 110.

107 O'Connor and Hermelin, Speech and Thought in Severe Subnormality.

108 Royal Society Archives (RSA) Uta Frith, personal archive (Box 1): 'Developments in British psychophysiology from the 1950s', by Peter Venables.

109 Lykken and Venables, 'Direct measurement of skin conductance'; Venables, 'Psychophysiology of abnormal behaviour'.

110 Hermelin and O'Connor, 'The response and self-generated behaviour of severely disturbed children'.

111 Hermelin and O'Connor, 'The response and self-generated behaviour of severely disturbed children'.

112 Hermelin and O'Connor, 'Effects of sensory input and sensory dominance'.

113 Hermelin and O'Connor, 'The selective visual attention of psychotic children'.

114 O'Connor, 'Visual input and social response in autistic children'.

115 Hermelin and O'Connor, 'Remembering of words by psychotic and subnormal children'.

116 Hermelin and O'Connor, Psychological Experiments with Autistic Children; Hermelin, 'Coding and immediate recall in autistic children', 564.

117 Vicedo, The Nature and Nurture of Love; Blum, Love at Goon Park.

118 Hermelin and O'Connor, 'Measures of distance and motility', 33.

119 Hermelin and O'Connor, 'Measures of distance and motility', 29, 33.

120 J. K. Wing, 'Diagnosis, epidemiology, aetiology', p. 6.

121 J. K. Wing, 'Diagnosis, epidemiology, aetiology', p. 7.

122 J. K. Wing, 'Diagnosis, epidemiology, aetiology', p. 11.

123 J. K. Wing, 'Diagnosis, epidemiology, aetiology'. 
124 Mittler, 'Psychological assessment', p. 147.

125 J. K. Wing, 'Diagnosis, epidemiology, aetiology'.

126 Hermelin and O'Connor, Psychological Experiments with Autistic Children.

127 Pick et al., 'Perceptual integration in children'.

128 Smith and Montessori, The Montessori System of Education.

129 Chapman, Constructive Evolution, p. 77; Piaget, La naissance de l'intelligence chez l'enfant.

130 Renshaw, 'The errors of cutaneous localization'; Pick et al., 'Perceptual integration in children'.

131 Berlucchi and Buchtel, 'Neuronal plasticity'.

132 Pick et al., 'Perceptual integration in children'.

133 Held, 'Plasticity in sensory-motor systems'.

134 NA/FD9/901: MRC Developmental Psychology Unit: Physiological Study with Autistic Children.

135 NA/FD9/901: MRC Developmental Psychology Unit: Physiological Study with Autistic Children.

136 Uta Frith Archive: Uta Frith, Notes for a talk at St Lawrence's Hospital, June 1968, p. 2.

137 Frith and Hermelin, 'The role of visual and motor cues', 153.

138 Frith and Hermelin, 'The role of visual and motor cues', 163.

139 Hermelin and Frith, 'Psychological studies of childhood autism', 115.

140 Hermelin and Frith, 'Psychological studies of childhood autism', 115.

141 Frith, 'Cognitive mechanisms in autism.

142 Martin, 'Sensory disorder in the autistic child', p. 295.

143 Ornitz, 'Childhood autism', p. 66.

144 L. Wing, 'Perceptual and language development in autistic children', pp. 173-195.

145 L. Wing, 'The handicaps of autistic children', 521.

146 MHCP/A: 644128: Report 20/5/65.

147 Institute of Psychiatry, Annual Report, 1964-1965, p. 14.

148 Kirman, 'Mentally handicapped persons', 688-689.

149 Kirman and Pare, 'Amine-oxidase inhibitors as possible treatment for phenylketonuria'.

150 Kirman, Mental Retardation; Kirman, Mental Handicap; Kirman, The Mentally Handicapped Child; Kirman, Science and Psychiatry.

151 Kirman, 'Autistic children', 727.

152 Wellcome Trust Archive PP/DWW/A/A/106: Winnicott paper to the Society for Autistic Children 1966. 
153 Tustin, Autism and Childhood Psychosis, p. 56.

154 Tustin, Autism and Childhood Psychosis, p. 74.

155 Tustin, Autism and Childhood Psychosis, pp. 29, 78.

$156 \mathrm{NA} / \mathrm{BD} 18 / 1438$.

157 NA/BD18/1438: Letter or note ref: PAS/PD From Dr Alwyn Smith (Senior Administrative MO) to Dr M. L. Cattell (Assistant senior admin MO), 26 February 1965.

158 MHCP/A: Rutter's files: 'Working paper on the place of child psychiatry in post-graduate training in general psychiatry', c.1968.

159 Rutter et al., 'A five to fifteen year follow up study of infantile psychosis', 1190.

160 Kolvin, 'Psychoses in childhood', p. 22.

161 Kolvin, 'Psychoses in childhood'.

162 Egdell and Kolvin, 'Childhood hallucinations', 279.

163 Rapoport et al., 'Autism spectrum disorders and childhood-onset schizophrenia'.

164 Rutter, 'Childhood schizophrenia reconsidered', 327; emphasis added.

165 Rutter, 'Childhood schizophrenia reconsidered', 327; Rutter, 'Diagnosis and Definition', 139.

166 Rutter, 'Childhood schizophrenia reconsidered'.

167 Kihlstrom, 'The cognitive unconscious'. 